\title{
VirION2: a short- and long-read sequencing and informatics workflow to study the genomic diversity of viruses in nature
}

\author{
Olivier Zablocki ${ }^{1,2}$, Michelle Michelsen ${ }^{3}$, Marie Burris ${ }^{1}$, Natalie Solonenko ${ }^{1}$, Joanna Warwick- \\ Dugdale $^{3,4}$, Romik Ghosh ${ }^{1}$, Jennifer Pett-Ridge ${ }^{5}$, Matthew B. Sullivan ${ }^{1,2,6}$, and Ben Temperton ${ }^{3}$ \\ ${ }^{1}$ Department of Microbiology, Ohio State University, Columbus, OH 43210, United States \\ ${ }^{2}$ Center of Microbiome Science, Ohio State University, Columbus, OH 43210, United States \\ ${ }^{3}$ School of Biosciences, University of Exeter, Stocker Road, Exeter, EX4 4QD, United Kingdom \\ ${ }^{4}$ Plymouth Marine Laboratory, Prospect Place, The Hoe, Plymouth PL1 3DH, United Kingdom \\ ${ }^{5}$ Physical and Life Sciences Directorate, Lawrence Livermore National Laboratory, Livermore, CA \\ 94550, United States \\ ${ }^{6}$ Department of Civil, Environmental and Geodetic Engineering, Ohio State University, Columbus, \\ $\mathrm{OH} 43210$, United States
}

* Corresponding Author:

Ben Temperton

b.temperton@exeter.ac.uk

\begin{abstract}
Microbes play fundamental roles in shaping natural ecosystem properties and functions, but do so under constraints imposed by their viral predators. However, studying viruses in nature can be challenging due to low biomass and the lack of universal gene markers. Though metagenomic shortread sequencing has greatly improved our virus ecology toolkit - and revealed many critical ecosystem roles for viruses - microdiverse populations and fine-scale genomic traits are missed. Some of these microdiverse populations are abundant and the missed regions may be of interest for identifying selection pressures that underpin evolutionary constraints associated with hosts and environments. Though long-read sequencing promises complete virus genomes on single reads, it currently suffers from high DNA requirements and sequencing errors that limit accurate gene prediction. Here we introduce VirION2, an integrated short- and long-read metagenomic wet-lab and informatics pipeline that updates our previous method (VirION) to further enhance the utility of longread viral metagenomics. Using a viral mock community, we first optimized laboratory protocols (polymerase choice, DNA shearing size, PCR cycling) to enable $76 \%$ longer reads (now median length of 6,965 bp) from 100-fold less input DNA (now 1 nanogram). Using a virome from a natural seawater sample, we compared viromes generated with VirION2 against other library preparation options (unamplified, original VirION, and short-read), and optimized downstream informatics for improved long-read error correction and assembly. VirION2 assemblies combined with short-read based data ('enhanced'viromes), provided significant improvements over VirION libraries in the recovery of longer and more complete viral genomes, and our optimized error-correction strategy using long- and short-read data achieved $99.97 \%$ accuracy. In the seawater virome, VirION2 assemblies captured 5,161 viral populations (including all of the virus populations observed in the other assemblies), $30 \%$ of which were uniquely assembled through inclusion of long-reads, and $22 \%$ of the top $10 \%$ most abundant virus populations derived from assembly of long-reads. Viral populations unique to VirION2 assemblies had significantly higher microdiversity, which may explain why short-read virome approaches failed to capture them. These findings suggest the VirION2 sample prep and workflow (updated at protocols.io) can help researchers better investigate the virosphere, even from challenging low-biomass samples. Our new protocols are available to the research community on protocols.io as a 'living document' to facilitate dissemination of updates to
\end{abstract}


keep pace with the rapid evolution of long read sequencing technology. Taken together, the addition of long-reads uniquely enabled the recovery of $22 \%$ of the most abundant viruses - that would have been missed in short-read only assemblies.

\section{INTRODUCTION}

Microbes are recognized as a major driving force in the functioning and maintenance of most ecosystems (Cavicchioli et al., 2019), however research in the past decade suggests viruses - mostly those that infect bacteria ('phages') - are equally important. In the world's oceans, viruses (mostly dsDNA phages) modulate microbial gene flow and are integral to global oceanic nutrient cycles (Brum et al., 2015; Roux et al., 2016; Gregory et al., 2019). Because most viruses are uncultivated, advances have mainly arisen through metagenomic approaches, which have rapidly improved with new sequencing technologies (Brum \& Sullivan, 2015). The importance of viruses in community composition and nutrient cycling is also increasingly being recognized across diverse ecosystems, including soils (Emerson et al., 2018; Trubl et al., 2018), the human microbiome (Shkoporov et al., 2019), glacial ice (Zhong et al., 2020), and invertebrates (Shi et al., 2016; Wolf et al., 2020). For example, viruses have the potential to aid in soil carbon flux by encoding plant polysaccharidedegrading enzymes (Emerson et al., 2018), or can be involved in human gut dysbiosis that leads to various health issues (Mirzaei \& Maurice, 2017).

Just as the scalability afforded by Illumina over 454 sequencing catapulted viromics from "gene ecology" to "population-based or genome-resolved ecology" (Brum \& Sullivan, 2015), long-read sequencing offers promise for another transformative step forward (Warwick-Dugdale et al., 2019). Recent evidence suggests that current short-read-sequencing metagenomic methods are not capturing the whole of the virosphere. Within dsDNA viruses, the most extensively studied, short-read metagenomes capture abundant viruses at the taxonomic level of species or genera, but not likely genotypes. This is because complex virus communities contain mixtures of strains, but assemblers cannot reconstruct individual strains - instead strain mixtures are collapsed into a single 'consensus' genome or multiple genome fragments (Nurk et al., 2017), thus masking strain-specific features that indicate the functional diversity within viral community members (Nelson et al., 2016). Though the extent of populations missed is unknown, two separate studies - one using single-cell genomics (Martinez-Hernandez et al., 2017) and the other long-read sequencing (Warwick-Dugdale et al., 2019) - have demonstrated that strain-level diversity is under-represented in short-read datasets (with 3-fold higher nucleotide diversity captured in long-read viral metagenomes compared to short-read viral metagenomes; (Warwick-Dugdale et al., 2019)). Specifically, both studies demonstrate that high genome microdiversity (i.e., the level of intra-population nucleotide variants for a virus 'species') could act as a barrier to full genome assembly, while masking co-occurring population variants.

We previously introduced VirION (Warwick-Dugdale et al., 2019), a custom library sequencing and informatics workflow that leveraged the strengths of both short- and long-read sequencing to increase capture of complete genomes (two-fold) and improve both the length and number of recovered nichedefining hypervariable islands. However, the input DNA requirement ( $100 \mathrm{ng}$ extracted from $20 \mathrm{~L}$ of seawater) for VirION is a barrier to generating long-read virome data from samples that yield little viral DNA, either due to challenges in extraction and/or low-volume, high resolution sampling. Here, we introduce VirION2, which includes significant wet-lab and analytical optimizations to reduce input DNA and increase long-read lengths and accuracy. We applied this new workflow to a concentrated natural seawater virioplankton community to assess VirION2's effectiveness at capturing community features relative to VirION and other short-read approaches. 
bioRxiv preprint doi: https://doi.org/10.1101/2020.10.28.359364; this version posted October 28, 2020. The copyright holder for this preprint (which was not certified by peer review) is the author/funder, who has granted bioRxiv a license to display the preprint in perpetuity. It is made available under aCC-BY-ND 4.0 International license.

\section{MATERIALS AND METHODS}

\section{Phage mock community and DNA extraction}

Three Pseudoalteromonas phage isolates (PSA-HM1, PSA-HP1 and PSA-HS2; see Supplementary Table 1 for more details) were used as a mock community. Each phage was grown in culture and genomic DNA extracted as previously described (Duhaime et al., 2017). To produce the mock community, equimolar DNA concentrations from each phage extract were mixed. This mixture was used as template for sequencing library preparation in all sequencing runs for optimizing VirION2 library preparation.

\section{Library preparations prior to Nanopore sequencing}

Three DNA library preparations were used: (1) Direct sequencing of DNA with no PCR amplification and no shearing of viral DNA (referred to as 'unamplified'), followed by the manufacturer's sequencing library protocol (see below for sequencing library preparation). (2) The VirION pipeline, performed as previously described (Warwick-Dugdale et al., 2019). Briefly, this entailed shearing of high-molecular weight DNA, followed by ligation of amplification primers and PCR amplification of the sheared DNA prior to applying the manufacturer's library protocol for sequencing. (3) VirION2, performed as follows: From the DNA extract, $10 \mu 1$ were set aside for short-read sequencing, and the remainder was sheared to $10 \mathrm{kbp}$ or $15 \mathrm{kbp}$ fragments with Covaris g-tubes according to the manufacturer's instruction (except for the $15 \mathrm{kbp}$ treatment, in which the samples were spun at 2,075 $\times g$ for $60 \mathrm{sec}$ ). Fragmented DNA was repaired and dA-tailed using the NEBNext FFPE DNA Repair Mix and NEBNext Ultra II End Repair/dA-Tailing Module, according to the manufacturer's instructions except incubation time, which was reduced from thirty to five minutes. The repaired DNA was cleaned using Ampure Beads (Beckman Coulter) according to the manufacturer's instructions (except for the final incubation time, in which $55^{\circ} \mathrm{C}$ was used instead of room temperature) at a 1:1 ratio (v/v) and eluted in nuclease-free water. Ligation of barcoded adapters (Oxford Nanopore PCR Barcoding Expansion 1-12 kit, cat\# EXP-PBC001) used for linker-amplified shotgun library (LASL) amplification was implemented as follows: A reaction mix composed of 50 $\mu 1$ NEB Blunt / TA Ligase master mix, 20 $\mu 1$ of the Oxford Nanopore barcode, and $30 \mu 1$ of cleaned DNA was incubated for ten minutes at room temperature. The DNA was then immediately cleaned with Ampure beads with 1:0.4 sample to bead ratio to remove short fragments, and eluted in $15 \mu 1$ nuclease-free water at $55^{\circ} \mathrm{C}$. PCR amplification on the cleaned libraries was performed as follows: A reaction mix using LA Takara Hot Start kit (Takara Bio) was prepared according to the manufacturer's instructions, using $5 \mu \mathrm{l}$ of cleaned DNA and $2 \mu \mathrm{l}$ of the desired barcode (from the same Oxford Nanopore barcoding kit, as previously). Cycling conditions were $94^{\circ} \mathrm{C}$ for 1 minute, 15 cycles of $94^{\circ} \mathrm{C}$ for $30 \mathrm{sec}, 62^{\circ} \mathrm{C}$ for $30 \mathrm{sec}, 68^{\circ} \mathrm{C}$ for $8-16$ minutes, and final elongation for $8-16 \mathrm{~min}$ at $72^{\circ} \mathrm{C}$. Elongation times varied according to the desired amplicon size: $8 \mathrm{~min}$ for $10 \mathrm{kbp} ; 12 \mathrm{~min}$ for $15 \mathrm{kbp}$; and $16 \mathrm{~min}$ for $20 \mathrm{kbp}$. Amplicons were subsequently cleaned with Ampure beads using a 1:0.5 sample to bead ratio, and eluted in $20 \mu 1$ nuclease-free water. The cleaned amplified libraries were then used as input for the 1D genomic DNA by ligation kit (SQK-LSK109, Oxford Nanopore Technologies) according to the manufacturer's instructions, with some modifications. In the 'DNA repair and end-prep' step, DNA CS (a standard DNA sequence for quality control by ONT) was excluded, and instead, $48 \mu 1$ of input DNA was added. In addition, incubation temperature was increased to $25^{\circ} \mathrm{C}$ from $20^{\circ} \mathrm{C}$. In the 'Adapter ligation and clean-up' step, the Long Fragment Buffer ('LFB') was used to enrich for longer fragments. In the bead resuspension step, pellet resuspension was incubated for 10 minutes at $55^{\circ} \mathrm{C}$ (instead of room temperature) since better DNA dissociation 
bioRxiv preprint doi: https://doi.org/10.1101/2020.10.28.359364; this version posted October 28, 2020. The copyright holder for this preprint (which was not certified by peer review) is the author/funder, who has granted bioRxiv a license to display the preprint in perpetuity. It is made available under aCC-BY-ND 4.0 International license.

from the beads was observed to be more efficient at a higher temperature (data not shown). The remainder of the protocol was unchanged.

\section{Mock community sequencing tests}

We tested four high-fidelity and/or long-range DNA polymerases in duplicate to evaluate improvements of read length during the amplification step: 1) NEBNext (NEB M0541), 2) NEB Q5 (NEB M0491), 3) NEB LongAmp (NEB M0287) and 4) TaKaRa LA Taq (TaKaRa RR042). For each library, 15 amplification cycles were used and input DNA (mock community phage genomes) was sheared at $10 \mathrm{kbp}$ (using Covaris g-TUBE). Influence of initial shearing length was also tested at $15 \mathrm{kbp}$ with a DNA input of $80 \mathrm{ng} / \mu 1$. For TaKaRa LA Taq, we also tested a shearing length of $15 \mathrm{kbp}$ using $1 \mathrm{ng}$ of input DNA to evaluate efficiency of VirION2 when minimal input DNA was available. For PCR cycling tests, $1 \mathrm{ng}$ of input DNA sheared at $15 \mathrm{kbp}$ was used as template.

\section{Preparation of viral DNA from Western English Channel}

20 L of seawater from the Western English Channel ('WEC') was collected in rosette-mounted Niskin bottles at a depth of $5 \mathrm{~m}$ from the Western Channel Observatory (WCO; http://www.westernchannelobservatory. org.uk/) coastal station 'L4' $\left(50^{\circ} 15.00 \mathrm{~N} ; 4^{\circ} 13.00 \mathrm{~W}\right)$ on $11^{\text {th }}$ February 2019. Seawater was placed in a coolbox at ambient temperature and upon return to shore, was transported to the University of Exeter for processing within six hours of collection. The cellular fraction was removed via sequential filtration through glass fiber (GF/D: pore size $2.7 \mu \mathrm{m}$ ) and polyethersulfone (pore size $0.22 \mu \mathrm{m}$ ) filters in a $142 \mathrm{~mm}$ polycarbonate rig with a peristaltic pump. Viruses were precipitated and concentrated from the filtrate by iron chloride flocculation and collected on $1.0 \mu \mathrm{m}$ polycarbonate filters (John et al., 2011). The viruses were immediately resuspended in ascorbate-EDTA buffer (0.1 M EDTA, $0.2 \mathrm{M} \mathrm{MgCl}_{2}, 0.2 \mathrm{M}$ ascorbic acid, pH 6.0) using $2 \mathrm{~mL}$ of buffer per $1 \mathrm{~L}$ of seawater. The resuspended viral fraction was transferred equally to four Amicon Ultra 100kDa centrifugal filter units (Millipore UFC910024) which had been pre-treated with $1 \%$ bovine serum albumin buffer to reduce capsid-filter binding (Deng et al., 2014) and flushed with SM buffer $\left(0.1 \mathrm{M} \mathrm{NaCl} ; 0.05 \mathrm{M}\right.$ Tris- $\left.\mathrm{HCl} ; 0.0008 \mathrm{M} \mathrm{MgCl}_{2}\right)$. The resuspended viral fraction was concentrated to 500-600 $\mu \mathrm{l}$ and removed from the filter unit; the Amicon filters were then washed with $200 \mu$ l of SM buffer (Bonilla et al., 2016) to ensure resuspension of all viral particles from capsid-filter adhesion. The viral fraction was purified with DNase $1(100 \mathrm{U} / \mathrm{mL} ; 2$ hours at room temperature) to remove non-encapsulated DNA. DNase 1 activity was terminated by the addition of 0.1 M EGTA and 0.1 M EDTA (Hurwitz et al., 2013). Viral DNA was extracted from the concentrated and purified viral fraction using Wizard DNA Clean-Up System (Promega A7280) to remove PCR inhibitors (John et al., 2011). The viral DNA was cleaned and concentrated by a $1.5 \times$ Ampure bead cleanup for downstream application.

\section{Long and short read processing of Western English Channel viral DNA}

Viral DNA from the WEC was used to prepare three separate long-read sequencing libraries and one short-read only library for comparison and error correction. (1) VirION libraries were prepared as described previously (Warwick-Dugdale et al., 2019), using $100 \mathrm{ng}$ of input DNA; (2) Unamplified sequencing of viral DNA was performed using $\sim 3 \mu \mathrm{g}$ of unsheared input DNA in a LSK-SQK109 library preparation (ONT) for genome sequencing according to the manufacturer's instructions, and sequenced on a MinION R9.4 revD flowcell for 48 hours. (3) A VirION2 library was prepared by first treating the DNA with the Zymo DNA Clean \& Concentrator Kit (cat\# D4013) according to the manufacturer's instructions. The clean concentrate $(90 \mu$, final concentration of $14.6 \mathrm{ng})$ was then 
bioRxiv preprint doi: https://doi.org/10.1101/2020.10.28.359364; this version posted October 28, 2020. The copyright holder for this preprint (which was not certified by peer review) is the author/funder, who has granted bioRxiv a license to display the preprint in perpetuity. It is made available under aCC-BY-ND 4.0 International license.

sheared into $15 \mathrm{kbp}$ fragments, used as template for 15 PCR cycles, and processed for MinION sequencing on a single flowcell according to the manufacturer's instructions with the modifications stated in the previous section ("Library preparations prior to Nanopore sequencing"); (4) Short Read sequencing was performed using $51 \mathrm{ng}$ of input DNA in a 1S Plus (Swift Biosciences) library preparation and sequenced to a depth of $\sim 25 \mathrm{M} 2 \mathrm{x} 125 \mathrm{bp}$ paired end sequencing on a HiSeq 2500 at the University of Exeter.

\section{Long-read processing and quality control}

Raw fast5 files containing ONT reads were basecalled with Guppy v2.3.1 (ONT), using the flip-flop model. Reads were allocated into barcode bins by porechop (Wick, 2017), using -require_two_barcodes, --discard_unassigned and --discard_middle parameters in order to limit library cross-talk in multiplexed samples, and to remove concatenated reads where two strands pass through the same pore in quick succession. NanoFilt 2.2.0 (De Coster et al., 2018) was used to trim the first 50 bases of reads (to ensure any residual barcode sequence removal) and remove reads $<1 \mathrm{kbp}$ or with a phred quality score $<9$. Chimeric PCR products were identified for quantification and subsequent removal from each demultiplexed run using yacrd (Marijon, Chikhi \& Varré, 2020) with default parameters. Remaining reads were kept for further analysis. To compare read lengths between mock community datasets, we randomly subsampled the reads (with replacement) using the 'sample' package in $\mathrm{R}$ version 3.5.0. Differences in bootstrapped medians ( $\mathrm{n}=50,000,1000$ replicates) between the barcoded libraries associated with each treatment (DNA polymerase type, DNA shearing size and PCR cycling number) were plotted as boxplots with the R package 'ggpubr'.

\section{Assessing assembly and error profiles}

For testing assembly performance of the WEC sample, reads that passed quality control (described above) were first sub-sampled using bbtools reformat (Bushnell, 2015) in order to mitigate library size bias in assembly comparisons. Sub-sampling was based on the number of reads in the smallest library $(500,000$ reads in the unamplified dataset). We compared median read length between the full datasets and the sub-sampled datasets to confirm subsampling had not biased read length distributions

(Supplementary Figure 1), and observed negligible shifts between full and sub-sampled datasets in both VirION (median read length: 3,020-3,023bp 95\% CI and 3,018-3,027bp 95\% CI) and VirION2 datasets (3,906-3,916bp 95\% CI and 3,900-3,917bp 95\% CI). Subsampled reads were used in three assembly approaches to determine optimal assembly strategy: (1) Overlap-layout consensus assembly ('OLC'): All-vs-all alignments were generated using minimap2 v2.17-r941 (Li, 2018), and used to build an assembly with Miniasm v0.3-r179 (Li, 2016). Minipolish v0.1.2 (Wick \& Holt, 2020) was used to iteratively apply Racon-based contig polishing (Vaser et al., 2017) on Miniasm assemblies. Polished OLC assemblies in GFA format were converted to FASTA using the following awk command: “ '\$1 /S/ \{print ">"\$2" $\backslash n$ "\$3\}' assembly.gfa > assembly.fasta” . Fasta-formatted Racon assemblies were further error-corrected with Medaka v0.11.5 (Oxford Nanopore Technologies Ltd., 2018), with an appropriate model select to correspond to the sequencing chemistry and basecaller model used. Lastly, Pilon v1.23 (Walker et al., 2014) was used to correct errors using short-read mapping information to the polished long-read assemblies. Briefly, short reads were mapped using BWA-MEM v0.7.17-r1 198 (Li, 2013) to the Medaka-corrected assemblies, and the resulting bam files were used in a single iteration of Pilon correction (using --fix all). (2) Flye assembly: Reads were first assembled into unitigs using the --nano-raw and --meta parameters in Flye v2.5 (Kolmogorov et al., 2019), with an estimated assembly size of $15 \mathrm{M}$. Medaka and Pilon were then used to correct Flye assemblies as previously described. (3) Hybrid SPAdes assembly: Hybrid assemblies were generated 
bioRxiv preprint doi: https://doi.org/10.1101/2020.10.28.359364; this version posted October 28, 2020. The copyright holder for this preprint (which was not certified by peer review) is the author/funder, who has granted bioRxiv a license to display the preprint in perpetuity. It is made available under aCC-BY-ND 4.0 International license.

with hybridSPAdes v3.12.0 (Antipov et al., 2016), using the --meta and --nanopore parameters. For comparison and evaluation of error in long-read assemblies, short-read only assemblies were assembled with metaSPAdes v3.12.0 (Nurk et al., 2017) with default parameters. The error-correction performance (number of mismatches and indels) of each long-read assembly/error-correction strategy (and intermediary stages) was assessed with Quast v4.5 (Gurevich et al., 2013) using the -meta option with default parameters against the matching short-read only assembly of the same WEC sample. Genome completeness was computed using CheckV v0.3.0 (Nayfach et al., 2020). Per contig median microdiversity $(\pi)$ was computed from single nucleotide polymorphism (SNP) frequencies as described previously (Warwick-Dugdale et al., 2019).

Generating 'enhanced' viromes with short- and long-read assemblies

To produce 'enhanced' virome datasets, each assembly type (i.e., metaSPAdes, hybridSPAdes, longread 'OLC') were independently searched for virus contigs (contigs $\geq 2.5 \mathrm{kbp}$ ) using VirSorter v1.0.5 (Roux et al., 2015) in --virome search mode. In each assembly type, only viral contigs $\geq 5 \mathrm{kbp}$ belonging to VirSorter categories 1, 2, 4, and 5 were kept. Filtered virus contigs from each assembly were pooled and subsequently dereplicated into viral populations with ClusterGenomes (Roux, 2015), using 70\% coverage and 95\% nucleotide identity clustering thresholds (sensu (Brum et al., 2015)).

\section{RESULTS AND DISCUSSION}

\section{Experimental overview}

Two sets of experiments were performed (Figure 1) to evaluate and optimize our long-read laboratory protocol in terms of increased read length, reduced DNA input requirements, and minimized error in assembled genomes. Experiment 1 sought to maximize read length and minimize chimera formation from sheared, amplified DNA extracted from a mock community of cultured phages. This community contained a representative member of the main families of tailed phages (Myoviridae, Siphoviridae, and Podoviridae) and ranged in genome sizes (38.2kbp - $129.4 \mathrm{kbp})$ and GC content (35.7\% - 44.7\%) (see Methods, Figure 1A, and Supplementary Table 1). We evaluated four DNA polymerases (Experiment 1A) using input material sheared to $10 \mathrm{kbp}$; optimized DNA shearing size to generate long-read viromes from a natural seawater sample (Experiment $1 B$ ), and evaluated the influence of the number of PCR cycles of chimera formation and read length (Experiment 1C). In Experiment 2 we optimized informatic approaches to maximize viral genome recovery and reduce error using the longread virome datasets from Experiment $1 \mathrm{~B}$ in combination with short-reads. We evaluated two assembly/error-correction strategies (Experiment $2 A$ ) and benchmarked these against assemblies from short-read approaches, which were assumed to have negligible sequencing error (Experiment $2 B$ ).

\section{Experiment 1A: Amplification with TaKaRA LA yields highest median read lengths}

Among the four polymerases tested, amplification with TaKaRa LA Taq yielded the highest median read length $(6,965 \mathrm{bp} ; 6,957-6,97395 \% \mathrm{CI})$. This was a significant increase $(\mathrm{p}<0.0001)$ of 2,866 bp compared to the performance of NEBNext used in the VirION workflow (Warwick-Dugdale et al., 2019), but retained a low proportion of chimeric reads $(0.08-0.19 \%)$. Therefore, we proceeded with TaKaRa LA Taq for all subsequent tests.

Experiment 1B: Longest read lengths are achieved at low DNA concentrations sheared to $15 \mathrm{kbp}$ 
We next sought to evaluate if increased fragment length of $15 \mathrm{kbp}$ provided a concomitant increase in final read length compared to $10 \mathrm{kbp}$, and whether this was also compatible with low-input DNA concentrations typical of some environmental viromes. Previous work using VirION had shown a discrepancy between expected fragment length ( $\sim 8 \mathrm{kbp})$ and final median read lengths ( $\sim 4.1 \mathrm{kbp})$, suggesting that longer fragments do not necessarily yield significantly longer reads. Final read length may be constrained by the amplicon size produced by the DNA polymerase or preferential amplification of smaller fragments (Shagin et al., 1999; Warwick-Dugdale et al., 2019). Here, shearing $80 \mathrm{ng}$ of input DNA to $15 \mathrm{kbp}$ reduced final median read lengths $(6,240 \mathrm{bp} ; 6,238 \mathrm{bp}-6,242$ bp $95 \% \mathrm{CI}$ ) in comparison to the 10kbp shearing treatment (median: 6,965 bp; see Experiment $1 \mathrm{~A}$ )

(Figure 2B). However, the longest median read lengths were observed when 1 ng of input DNA was sheared to $15 \mathrm{kbp}$ (median: 7,223bp; 6,899 - 7,540 bp 95\% CI), an increase of $216 \mathrm{bp}$ and $983 \mathrm{bp}$ over shearing $80 \mathrm{ng}$ DNA to $10 \mathrm{kbp}$ and $15 \mathrm{kbp}$, respectively. There was significant variance in read length between replicates (Figure 2B), suggesting that: (1) final read lengths may strongly influenced by variance in downstream library preparation flowcell properties; (2) Interactions between input DNA and centrifugal force selected for shearing may be complex. Both DNA inputs $<100 \mathrm{ng}$ and a shear size of $15 \mathrm{kbp}$ are outside the official parameters of Covaris g-tube specifications. Therefore, additional optimizations may be required to reduce variance between samples.

To assess our revised protocol on real world samples, three long-read libraries (from $14.6 \mathrm{ng}$ of input DNA) from a virus-enriched marine were generated and sequenced (Figure 2C). These libraries were (1) a 'no amplification' library ('unamplified'), (2) our previous VirION protocol, and (3) this study ('VirION2'). The 'unamplified' library had the highest median (5,601 bp; 5,560 bp - 5,645 bp 95\% $\mathrm{CI})$. Between the amplified datasets, the read size distribution from the VirION2 library was significantly higher than VirION. However, in both libraries read sizes were generally lower than those observed in the mock community (at identical shearing size), a phenomenon also observed in our previous study (Warwick-Dugdale et al., 2019). This is likely due to shearing and/or degradation during the $\mathrm{FeCl}_{3}$ precipitation, giving smaller fragments for amplification in the natural sample. Further optimization into maximizing DNA integrity from viral metagenomes could be beneficial to improving long-reads.

\section{Experiment 1C: VirION2 libraries can be prepared with very low input DNA and increased PCR cycles without increasing chimeric reads}

Samples with low DNA concentrations require increased numbers of PCR cycles to meet the input requirements $(1 \mu \mathrm{g})$ of Nanopore sequencing. To maximize VirION2's applicability to various sample types, including those with very low input DNA concentrations ( $\sim 1 \mathrm{ng})$, we next tested how amplification cycling $(15,18,20$, and 22 cycles with TaKaRa LA Taq) impacted read lengths and chimeras (Figure 2D). Starting with the mock community DNA at 1ng concentration, the 20-cycle treatment generated significantly longer reads compared to all other treatments (Wilcoxon rank test, $p$ $<2.22 \times 10^{-16}$; median $=8,125 \mathrm{bp}$ ). Across all treatments and replicates in this experiment, the number of chimeric reads remained near constant (range: $0.01-0.04 \%$ ) and therefore, at least within the range tested here, is not an obstacle to increasing cycle number to generate sufficient DNA for sequencing.

\section{Experiment 1 conclusions}

Together, the optimization of experiment 1 improve the VirION method in two critical ways. First, the median read length was significantly increased $(p<0.0001)$ by $76 \%$ over the original VirION 
approach. Second, we were able to generate long-read data from 1ng libraries with a negligible number of chimeric reads, which removed the one microgram requirement for standard MinION libraries, and reduced VirION's DNA input requirement 100-fold (Warwick-Dugdale et al., 2019). These laboratory protocol improvements should permit a broader diversity of samples to be investigated with long-read sequencing technology. Since Nanopore sequencing is constantly evolving, we have posted the VirION2 method at protocols.io to ensure continued protocol development as the research community identifies new opportunities.

\section{Experiment 2 - Informatics benchmarking}

In a second experiment (Figure 1B), we assessed two informatic approaches for combining long- and short-read data to maximize recovery and accuracy of viral genomes from natural viral communities. A single, virus-enriched seawater sample ('WEC'; see Methods and Experiment 1B) was used, along with the corresponding Illumina short-reads. Adding short reads served two purposes: 1) as a gold standard for long-read sequencing accuracy estimates and 2) for use in hybrid assemblies and error correction of long-read assemblies.

\section{Experiment 2A: Performance of long-read assemblers and error-correction tools.}

We first tested an 'overlap-layout consensus' ('OLC strategy') assembly approach (performed by Miniasm), followed by the successive application of three error-correction tools: Racon, Medaka, and Pilon (the latter uses short-read correction). Of note, assembly of long-read data from this study with Canu (Koren et al., 2017), used in VirION (Warwick-Dugdale et al., 2019) failed to finish running within $48 \mathrm{~h}$ wall time on an high-performance computing node with $48 \mathrm{CPU}$ cores and 1Tb RAM (data not shown), likely due to the high volume of data generated in contemporary MinION runs (Amarasinghe et al., 2020). In the 'OLC strategy', Racon was used to correct raw contigs by generating genomic consensus through multiple iterations of long-read self-mappings, however there is no set standard for how many rounds of Racon to use. Therefore, we first assessed the impact of Racon iterations on error correction by testing 1,2,3,5 and 10 rounds of Racon polishing. Two rounds of polishing were sufficient to produce a sharp decrease ( 2 - 3-fold drop) into the number of mismatches (per 100kbp of sequence), while a single round resulted in a $5-8.5$-fold reduction in insertion/deletion ('indels') events (Supplementary Figure 2A). Further rounds of polishing made no significant difference to the number of mismatches and indels removed. Concomitantly, a single round of polishing significantly improved median predicted protein lengths from 71 a.a to 107 a.a but additional rounds resulted in no significant improvements (Supplementary Figure 2B). Next, we estimated the effectiveness of error correction between three types of long-read libraries prepared from the same WEC sample (i.e., 'unamplified', 'VirION and 'VirION2'), compared to short-read only assemblies. Applying Medaka and Pilon provided a moderate reduction (range: $2-13 \%$ ) of mismatches and a major reduction in indels (range: 70-73\%; Supplementary Figure 3A) across all three library types. Short-read error correction of long-read assemblies with Pilon had the greatest impact in partially restoring the expected median protein size of 142 aa predicted from short-read only data (dotted line, Supplementary Figure 3B). This was most effective in the VirION2 library, reaching 131 aa median size $(130-132$ aa $95 \% \mathrm{CI})$, compared to 113 aa $(112-115$ aa $95 \% \mathrm{CI})$ in VirION and 112 aa (111 - 113 aa 95\% CI) in the 'unamplified' dataset. Therefore OLC assembly of VirION2 reads, coupled with two rounds of Racon polishing, followed by one round of Medaka and additional short-read polishing with Pilon is our recommended approach, and yielded the most improved assembly correction between the three long-read libraries, as well as reaching median protein size closest to the short-read assembly. 
We next tested the effectiveness of assembly by repeat graphs using Flye (see Methods) to process our virome. Recent reports (De Maio et al., 2019; Moss, Maghini \& Bhatt, 2020) suggest good performance in terms of assembly accuracy and scale in prokaryotic datasets, however its performance with viromes remains untested. Assembly of WEC long-read datasets with Flye was followed by the same error-correction tools as described for 'OLC strategy', except for Racon (Racon is designed for Miniasm only, and Flye has an internal error-correction module). Despite repeated attempts and large computing allowances (48 CPU cores/1Tb RAM), we could not generate a Flye assembly from the 'unamplified' library. This could be due either to sequence complexity in the sample, which can complicate estimating the required genome size parameter of the program, and/or insufficient resources to run (Wick \& Holt, 2020). However, both VirION and VirION2 datasets were successfully assembled by Flye without large resources, therefore we focused our analysis on these. Similar to the OLC strategy, indel reduction was more successful (range: 74-75\% removed) compared to mismatches. Surprisingly, mismatches in Flye-assembled contigs marginally increased with polishing by Medaka - a feature that was not entirely corrected with subsequent application of shortread polishing with Pilon, resulting in an overall 1.25\% removal in VirION2 only, but an increase of $4.53 \%$ in VirION) (Supplementary Figure 3C and Supplementary Table 2). Corrected Flye assemblies had shorter median protein sizes compared to the OLC strategy results in both VirION and VirION2 datasets (by 5 and 21 amino acids, respectively, Supplementary Figure 3D), perhaps due to greater indel reduction in the OLC strategy. Therefore, in terms of correction performance, the OLC strategy is preferred over the Flye strategy, at least for assembly of long-read viral metagenomics with current software versions.

\section{Experiment 2B: VirION2 coupled with OLC assembly provides greatest gains in assembly and predicted gene lengths}

Using the results generated in experiment $2 \mathrm{~A}$, we compared all the corrected long-read assembly types to hybrid assemblies (i.e., short read assemblies scaffolded by long-reads) and short-read only assemblies (Figure 3). Across all assembly types (hybrid, OLC and Flye) and libraries (unamplified, VirION and VirION2), sequence accuracy of polished long-read assemblies ranged from $99.61 \%$ to 99.98\% (Supplementary Table 2). The VirION2 OLC strategy offered an increased accuracy of $\sim 0.05 \%$ over 'unamplified' and VirION-amplified reads. Although seemingly small, this increased accuracy translated into a much-improved median protein size of 131 aa $(130-132$ aa; 95\% CI), compared to 112 aa $(111-113$ aa; 95\% CI) in the unamplified library and 113 aa $(112-115$ aa; 95\% CI) for the VirION library. Regardless of library method, Flye assemblies consistently yielded the lowest median protein sizes. In terms of contigs lengths, N50 metrics were markedly improved ( 4fold) in all assembly strategies in comparison to short-read only assemblies (Supplementary Table 3). Between VirION and VirION2 specifically, the N50 from VirION2 contigs was superior in both OLC (31,496 bp versus 16,840 bp) and Flye strategies (31,130 bp versus 21,231 bp). The same was true for maximum contig sizes reached: 194,588 bp versus 115,168 bp (OLC), and 570,045 bp versus 140,205 bp (Flye). Overall, between library preparation (unamplified, VirION and VirION2) and long-read assembly/correction strategies (OLC and Flye), combining VirION2 with the OLC strategy performed best (99.71\% accuracy, Supplementary Table 2) and is the preferred option for accurate long-read virome datasets, with the critical advantage of lowering the input DNA requirement by 100 fold.

VirION2-enhanced viromes recovers longer and more microdiverse viral populations 
Next, we evaluated how well short- and long-read assemblies recovered viral populations from a natural viral community, in terms of genome size, genome completeness and microdiversity. Specifically, we compared a short-read-only virome against 'enhanced' viromes that maximize the benefits of both short- and long-read technologies (derived from combining multiple assemblies from both read types; see Methods and Figure 4A). Genome size, genome completeness, and microdiversity (i.e., intra-population genomic variation) were all significantly improved in VirION2enhanced viromes, compared to short-read and VirION-enhanced viromes (Figure 4 B -D, and Supplementary Table 4). Notably, recovery of $>100 \mathrm{kbp}$ genomes in the VirION2-enhanced virome was increased by 13- and 2-fold (Figure 4B), relative to short-reads only and VirION-enhanced, respectively. Accurate and contiguous assembly of large phage genomes could increase the detection of 'jumbo' phages throughout ecosystems, as there is currently limited data on the distribution and genome diversity for large phages (Yuan \& Gao, 2017; Al-Shayeb et al., 2020). Microdiversity (measured as $\pi$, Figure 4D) increased by 2.4 - 2.5-fold in both VirION- and VirION2- enhanced viromes, respectively, compared to the short-read assemblies. A similar increase was reported in the original VirION method from WEC seawater samples (3-fold; (Warwick-Dugdale et al., 2019)). However, there was no significant difference between VirION and VirION2 datasets (Mann Whitney U-test, $p$-value $=0.536$ ). Although it is tempting to speculate that residual sequencing error in longread datasets could artificially increase SNP frequency and therefore higher microdiversity $(\pi)$ values, we found that its impact is negligible due to the error-correction pipeline applied, along with the error distribution patterns (mostly indels) of Nanopore reads (for more details, see Supplementary Analysis 1). Alternatively, the higher microdiversity in 'enhanced' datasets compared to short-read data could be due to novel viral populations uniquely captured with long-reads (discussed below). In addition, it is worth noting that during the multiple rounds of polishing of long-read assemblies, genuine biological diversity may be removed from consensus sequences, leading to an underestimation of microdiversity.

\section{Long-read viromics improves capture of abundant viral populations compared to short-read only methods}

In addition to better genomic metrics, we assessed how the 'VirION2-enhanced' assembly from the WEC seawater sample could alter our biological interpretations of complex viral communities. We first evaluated if more viruses could be detected by adding long-reads, and by counting the number of shared and unique viruses in each constituent assembly that make the VirION2-enhanced virome (i.e., long-read only, short-read only, and hybrid). Among the total number of viral populations $(n=5,161)$, $68 \%$ were represented in all assembly types. Within the pool of viral populations observed only within a single assembly method, populations from the hybrid assembly were the majority (23\%), followed by the OLC assembly (7\%), and short read assembly (2\%). We surmise that adding long reads permitted a more complete view of a virome, and viral genomes that would otherwise have been missed by short-read assembly alone.

Next, we looked at patterns in abundance of viral populations as a function of assembly method within the VirION2-enhanced virome. (Figure 5A). Among all viruses, the majority of these unique viruses were low abundance populations, and were short fragments from the hybrid assembly. However, within the top $10 \%$ most abundant viruses $(n=516), 164$ were unique to a particular assembly method and $70 \%$ of these were derived from the long-read only assembly. Taken together, the addition of long-reads uniquely enabled the recovery of $22 \%$ of the most abundant viruses - that would have been missed in short-read only assemblies. We queried whether microdiversity could be a contributing factor as to why these unique viruses would be missed. Indeed, when we looked at the 
fraction of 'unique' viral populations within each assembly type in the 'enhanced' virome, unique viral populations had significantly higher microdiversity compared to the shared pool of viruses in each assembly, most predominantly observed in the 'OLC' assembly (Figure 5B). Thus, our data suggest that high intrapopulation nucleotide variation in a subset of virus genomes can lead to these genomes being fragmented (Roux et al., 2017) and overlooked in a short-read only viral metagenome experiment.

\section{Current limitations and future directions}

Despite the advances of VirION2, several limitations remain. First, an assembly step (due to the required shearing of input DNA), as well as corresponding short-reads, remain a necessity to ensure the highest level of error-correction, and to enable microdiversity estimates. Ongoing developments that increase recovery of full-length genomes as single long-reads and optionally use short-reads for correction (Beaulaurier et al., 2020) will certainly help. However, this workflow cannot be used for low-input samples, as it requires micrograms of high molecular weight DNA to yield full genomes as single reads. Moreover, even if sufficient DNA is obtained, our tests using 'unamplified' datasets indicated that compared to the VirION2 approach, viral populations from the unamplified library had shorter median proteins sizes (112 a.a versus 131 a.a, respectively. Second, the revised long-read library protocol was designed and evaluated for the recovery of dsDNA virus genomes. Future refinements could include modifying the current protocol for the inclusion of ssDNA and RNA genomes (through direct RNA or cDNA libraries). Third, due to the amplification step within the VirION2 laboratory protocol, we cannot leverage base modification capabilities from Nanopore sequencing, as these can only be detected if intact, non-amplified high molecular weight DNA is used as template for sequencing. Lastly, we have not evaluated VirION2 on the latest R10 flowcells, which promises further sequencing accuracy, especially within homopolymeric regions. Adapting VirION2 to R10 chemistry (R9.4 flowcells were used in this study) to generate long-read viromes, as well as sequencing depth available from the PromethION (the higher throughout version of the MinION sequencing platform) remain to be tested, but we do not anticipate major protocol (either wet-lab or informatics) modifications will be required. Lastly, additional laboratory optimizations parameters could be tested, including whether further increases in DNA shearing sizes (e.g., 20kbp or higher) may further improve long-read sizes, albeit with likely diminishing returns.

\section{Conclusions}

Though short-read sequencing has become the gold standard in viral metagenomics, it is increasingly clear that this approach does not capture the full extent of virus diversity. Specifically, intra-diversity differences between closely related viral populations (i.e., microdiversity) can cause genome fragmentation and mask genes under active selection pressures (e.g. genomic islands) and important indicators of virus-host dynamics. Long-read sequencing, combined with short-reads, can further increase estimates of viral diversity and capture ecologically important taxa. Owing to the substantial decrease in DNA requirements for VirION2, long-read viral metagenomics may now be applied to a broader range of samples, thus constituting an invaluable addition to our current viral ecogenomics toolkit for the better exploration of viromes and their impacts in nature.

\section{Acknowledgements}

The authors thank the crew of the Plymouth Marine Laboratory vessel 'Quest' for collection of seawater samples. Research was supported by high performance computing resources provided by the University of Exeter and the Ohio Supercomputer Center. 
bioRxiv preprint doi: https://doi.org/10.1101/2020.10.28.359364; this version posted October 28, 2020. The copyright holder for this

\section{Funding}

OZ, MBS and JPR were supported by the U.S. Department of Energy, Office of Biological and Environmental Research, Genomic Science Program 'Microbes Persist' Scientific Focus Area (award \#SCW 1632). MBS is supported by the U.S. Department of Energy, Office of Science, Office of Biological and Environmental Research, Genomic Science Program under Award Number DESC0020173 and by the Gordon and Betty Moore Foundation (grant \#5488). The efforts of JWD were funded by the Natural Environment Research Council GW4+ Doctoral Training Program (NE/L002434/1). MM and BT were funded by NERC (NE/R010935/1), with additional funding for BT provided by the Simons Foundation BIOS-SCOPE program. This project used equipment funded by the Wellcome Trust Institutional Strategic Support Fund (WT097835MF), Wellcome Trust Multi User Equipment Award (WT101650MA) and BBSRC LOLA award (BB/K003240/1). Work at Lawrence Livermore National Laboratory was conducted under the auspices of DOE Contract DEAC52-07NA27344.

\section{Figure and Table legends}

Figure 1. Overview of wet lab optimization experiments and informatic benchmarking. A) Laboratory optimization ('Experiment 1') in which a mock community of three phages was used to conduct three experiments aimed at producing longer reads from less input DNA. B) Informatics benchmarking ('Experiment 2') in which a seawater virome was sequenced with short-reads (Illumina) and long-read sequencing. Three distinct long-read libraries were generated, error-corrected and assembled, and were compared to short-read assemblies to assess accuracy and assembly performance.

Figure 2. Laboratory optimization yield longer reads from less DNA. A) Boxplots showing the median and quartiles of the read length distribution between four DNA polymerases. B) Boxplots showing the median and quartiles of the read length distribution between DNA shearing size treatments and one low-input DNA (1ng) variant of the $15 \mathrm{kbp}$ shearing treatment. C) Boxplots showing the median and quartiles of the read length distribution of three long-read library types, either unamplified or amplified (VirION and VirION2). D) Boxplots showing the median and quartiles of the read length distribution between four thermocycling treatments (here, number of cycles). Asterisks represent a significant difference $(p<0.0001)$ between pairs of replicate treatments where applicable.

Figure 3. Error-correction profiles between library methods and assembly strategies using the WEC sample. A) On the x-axis, mismatches and insertion/deletion ('indels') events according to assembly strategy (full OLC, full Flye, and Hybrid) are grouped separately, and divided into three facets, one for each long-read library method (unamplified, VirION, VirION2). The number of errors (y-axis) is scaled to the binary logarithm $(\log 2)$ for scale fitting purposes. B) Boxplot depicting the protein size distribution (in amino acids, denoted as 'a.a'; y-axis) derived from each library method (x-axis), each of which is sub-grouped per assembly strategy. In both A and B panels, there were no results from Flye assemblies for the raw datasets, as these could not be produced.

Figure 4. Comparison of virus genome properties between short-read and 'long-read-enhanced' viromes. A) Workflow to produce 'enhanced viromes', in which Spades, hybrid and long-read (OLC) viruses are combined to maximize the recovery of virus signals. B) Cumulative Distribution Function (CDF) plot depicting the frequency (y-axis) of virus genomes according to genome length (measured in kilo basepairs (kbp), $\mathrm{x}$-axis) between three assembly strategies. C) Cumulative Distribution 
bioRxiv preprint doi: https://doi.org/10.1101/2020.10.28.359364; this version posted October 28, 2020. The copyright holder for this preprint (which was not certified by peer review) is the author/funder, who has granted bioRxiv a license to display the preprint in perpetuity. It is made available under aCC-BY-ND 4.0 International license.

Function (CDF) plot depicting the frequency (y-axis) of virus genomes according to genome 'completeness' (measured in \%, x-axis) between three assembly strategies. D) Cumulative Distribution Function (CDF) plot depicting the frequency (y-axis) of virus genomes according to genome microdiversity per genome (measured as $\pi$, $\mathrm{x}$-axis) between three assembly strategies.

Figure 5. Additional insights are gained through a VirION2-enhanced assembly strategy. A) Rank abundance curve depicting the seawater virus community, colored according to whether a virus population (individual bars) was detected uniquely (turquoise) or in multiple (pastel red) assembly types. The top $10 \%$ most abundant viral populations are highlighted between dashed lines, where they are divided per assembly origin in the pie chart. B) Boxplots depicting the level of microdiversity between shared and unique viral populations within each constituent assembly present in the 'enhanced' dataset.

Supplementary Figure 1. Visualizing sub-sampling impacts on long-read size datasets. Frequency histograms depicting the read size distribution between the three long-read libraries: 'raw' (i.e., unamplified input DNA), VirION, and VirION2. Each library type is represented in its own facet, with both full (pastel red) and sub-sampled (turquoise) size distributions overlapping. Dotted lines and their associated colors denote the median value of each distribution.

Supplementary Figure 2. Impact of error-correction with the Racon tool using VirION2 data from a seawater sample ('WEC'). A) Bar chart depicting the number of mismatches and insertion/deletions (indels), grouped by number of Racon rounds (on the x-axis) across increasing iterations of Racon polishing of long-read assemblies. From light to dark blue, increasing color saturation corresponds to the increasing number of Racon polishing rounds (also applicable to panel B). B) Boxplot depicting the impact of consecutive rounds of Racon (x-axis) on predicted protein sizes (y-axis, measured in amino acids denoted as 'aa'). The horizontal dotted line represents the median protein size of the corresponding short-read assembly (142 amino acids).

Supplementary Figure 3. Error-correction levels at each correction stage within OLC and Flye strategies compared between long-read library methods. A) Bar chart depicting the number of mismatches and insertion/deletions (indels) from the OLC strategy, grouped according to increasing correction (on the x-axis), separated by library method (raw, VirION, VirION2). B) Boxplots depicting protein size distribution at each level of correction in the OLC strategy. The horizontal dotted line represents the median protein size of the corresponding short-read assembly (142 amino acids). C) Bar chart depicting the number of mismatches and insertion/deletions (indels) from the 'Flye' strategy, grouped according to increasing correction (on the x-axis), separated by library method (VirION and VirION2). D) Boxplots depicting protein size distribution at each level of correction in the 'Flye' strategy. The horizontal dotted line represents the median protein size of the corresponding short-read assembly (142 amino acids).

Supplementary Figure 4. Per-genome microdiversity distributions within the VirION2-enhanced viromes constituent assemblies.

Supplementary Table 1. Summary characteristics of the virus isolates used in the mock community for Experiment 1.

Supplementary Table 2. Error-correction performance benchmarks between assembly methods and sequencing libraries. 
bioRxiv preprint doi: https://doi.org/10.1101/2020.10.28.359364; this version posted October 28,2020 . The copyright holder for this preprint (which was not certified by peer review) is the author/funder, who has granted bioRxiv a license to display the preprint in perpetuity. It is made available under aCC-BY-ND 4.0 International license.

Supplementary Table 3. Contigs and protein statistics between assembly strategies above $2.5 \mathrm{kbp}$.

Supplementary Table 4. Genome-based metrics between Nextera-only and virION-enhanced datasets ( $>5 \mathrm{kbp}$ genomes).

Supplementary Table 5. Tracking SNP and microdiversity detection in mock community long-read assemblies at different stages of error correction.

\section{References}

Al-Shayeb B, Sachdeva R, Chen L-X, Ward F, Munk P, Devoto A, Castelle CJ, Olm MR, BoumaGregson K, Amano Y, He C, Méheust R, Brooks B, Thomas A, Lavy A, Matheus-Carnevali P, Sun C, Goltsman DSA, Borton MA, Sharrar A, Jaffe AL, Nelson TC, Kantor R, Keren R, Lane KR, Farag IF, Lei S, Finstad K, Amundson R, Anantharaman K, Zhou J, Probst AJ, Power ME, Tringe SG, Li W-J, Wrighton K, Harrison S, Morowitz M, Relman DA, Doudna JA, Lehours AC, Warren L, Cate JHD, Santini JM, Banfield JF. 2020. Clades of huge phages from across Earth's ecosystems. Nature 578:425-431. DOI: 10.1038/s41586-020-2007-4.

Amarasinghe SL, Su S, Dong X, Zappia L, Ritchie ME, Gouil Q. 2020. Opportunities and challenges in long-read sequencing data analysis. Genome Biology. DOI: 10.1186/s13059-020-1935-5.

Antipov D, Korobeynikov A, McLean JS, Pevzner PA. 2016. HybridSPAdes: An algorithm for hybrid assembly of short and long reads. Bioinformatics 32:1009-1015. DOI:

10.1093/bioinformatics/btv688.

Beaulaurier J, Luo E, Eppley JM, Uyl P Den, Dai X, Burger A, Turner DJ, Pendelton M, Juul S, Harrington E, DeLong EF. 2020. Assembly-free single-molecule sequencing recovers complete virus genomes from natural microbial communities. Genome Research 30:437-446. DOI: 10.1101/gr.251686.119.

Bonilla N, Rojas MI, Netto Flores Cruz G, Hung S-H, Rohwer F, Barr JJ. 2016. Phage on tap-a quick and efficient protocol for the preparation of bacteriophage laboratory stocks. PeerJ 4:e2261. DOI: $10.7717 /$ peerj.2261.

Brum JR, Ignacio-espinoza JC, Roux S, Doulcier G, Acinas SG, Alberti A, Chaffron S, Cesar Ignacio-Espinoza J, Roux S, Doulcier G, Acinas SG, Alberti A, Chaffron S, Cruaud C, De Vargas C, Gasol JM, Gorsky G, Gregory AC, Guidi L, Hingamp P, Iudicone D, Not F, Ogata H, Pesant S, Poulos BT, Schwenck SM, Speich S, Dimier C, Kandels-Lewis S, Picheral M, Searson S, Bork P, Bowler C, Sunagawa S, Wincker P, Karsenti E, Sullivan MB, Boss E, Follows M, Grimsley N, Jaillon O, Karp-Boss L, Krzic U, Raes J, Reynaud EG, Sardet C, Sieracki M, Stemmann L, Velayoudon D, Weissenbach J. 2015. Patterns and ecological drivers of ocean viral communities. Science 348. DOI: 10.1126/science.1261498.

Brum JR, Sullivan MB. 2015. Rising to the challenge: accelerated pace of discovery transforms marine virology. Nature Reviews Microbiology 13. DOI: 10.1038/nrmicro3404.

Bushnell B. 2015.BBMap

Cavicchioli R, Ripple WJ, Timmis KN, Azam F, Bakken LR, Baylis M, Behrenfeld MJ, Boetius A, Boyd PW, Classen AT, Crowther TW, Danovaro R, Foreman CM, Huisman J, Hutchins DA, Jansson JK, Karl DM, Koskella B, Mark Welch DB, Martiny JBH, Moran M, Orphan V, Reay D, Remais JV, Rich V, Singh BK, Stein LY, Stewart FJ, Sullivan MB, van Oppen MJH, Weaver SC, Webb EA, Webster N. 2019. Scientists' warning to humanity: microorganisms and climate change. Nature Review Microbiology In Press:1-9. DOI: .1037//0033-2909.I26.1.78. 
bioRxiv preprint doi: https://doi.org/10.1101/2020.10.28.359364; this version posted October 28,2020 . The copyright holder for this preprint (which was not certified by peer review) is the author/funder, who has granted bioRxiv a license to display the preprint in perpetuity. It is made available under aCC-BY-ND 4.0 International license.

De Coster W, D'Hert S, Schultz DT, Cruts M, Van Broeckhoven C. 2018. NanoPack: Visualizing and processing long-read sequencing data. Bioinformatics 34:2666-2669. DOI: 10.1093/bioinformatics/bty149.

Deng L, Ignacio-Espinoza JC, Gregory AC, Poulos BT, Weitz JS, Hugenholtz P, Sullivan MB. 2014. Viral tagging reveals discrete populations in Synechococcus viral genome sequence space. Nature 513:242-245. DOI: 10.1038/nature13459.

Duhaime MB, Solonenko N, Roux S, Verberkmoes NC, Wichels A, Sullivan MB. 2017. Comparative Omics and Trait Analyses of Marine Pseudoalteromonas Phages Advance the Phage OTU Concept . Frontiers in Microbiology 8:1241.

Emerson JB, Roux S, Brum JR, Bolduc B, Woodcroft BJ, Jang HB, Singleton CM, Solden LM, Naas AE, Boyd JA, Hodgkins SB, Wilson RM, Trubl G, Li C, Frolking S, Pope PB, Wrighton KC, Crill PM, Chanton JP, Saleska SR, Tyson GW, Rich VI, Sullivan MB. 2018. Host-linked soil viral ecology along a permafrost thaw gradient. Nat Microbiol 3:870-880. DOI: 10.1038/s41564-018-0190-y.

Gregory AC, Zayed AA, Conceição-Neto N, Temperton B, Bolduc B, Alberti A, Ardyna M, Arkhipova K, Carmichael M, Cruaud C, Dimier C, Domínguez-Huerta G, Ferland J, Kandels S, Liu Y, Marec C, Pesant S, Picheral M, Pisarev S, Poulain J, Tremblay JÉ, Vik D, Acinas SG, Babin M, Bork P, Boss E, Bowler C, Cochrane G, de Vargas C, Follows M, Gorsky G, Grimsley N, Guidi L, Hingamp P, Iudicone D, Jaillon O, Kandels-Lewis S, Karp-Boss L, Karsenti E, Not F, Ogata H, Poulton N, Raes J, Sardet C, Speich S, Stemmann L, Sullivan MB, Sunagawa S, Wincker P, Culley AI, Dutilh BE, Roux S. 2019. Marine DNA Viral Macro- and Microdiversity from Pole to Pole. Cell 177:1109-1123.e14. DOI: 10.1016/j.cell.2019.03.040.

Gurevich A, Saveliev V, Vyahhi N, Tesler G. 2013. QUAST: Quality assessment tool for genome assemblies. Bioinformatics 29:1072-1075. DOI: 10.1093/bioinformatics/btt086.

Hurwitz BL, Deng L, Poulos BT, Sullivan MB. 2013. Evaluation of methods to concentrate and purify ocean virus communities through comparative, replicated metagenomics. Environ Microbiol 15:1428-1440. DOI: 10.1111/j.1462-2920.2012.02836.x.

John SG, Mendez CB, Deng L, Poulos B, Kauffman AKM, Kern S, Brum J, Polz MF, Boyle EA, Sullivan MB. 2011. A simple and efficient method for concentration of ocean viruses by chemical flocculation. Environmental Microbiology Reports. DOI: 10.1111/j.17582229.2010.00208.x.

Kolmogorov M, Yuan J, Lin Y, Pevzner PA. 2019. Assembly of long, error-prone reads using repeat graphs. Nature Biotechnology 37:540-546. DOI: 10.1038/s41587-019-0072-8.

Koren S, Walenz BP, Berlin K, Miller JR, Bergman NH, Phillippy AM. 2017. Canu: Scalable and accurate long-read assembly via adaptive $\kappa$-mer weighting and repeat separation. Genome Research 27:722-736. DOI: 10.1101/gr.215087.116.

Li H. 2013. Aligning sequence reads, clone sequences and assembly contigs with BWA-MEM. arXiv preprint:1303.3997. DOI: arXiv:1303.3997 [q-bio.GN].

Li H. 2016. Minimap and miniasm: Fast mapping and de novo assembly for noisy long sequences. Bioinformatics. DOI: 10.1093/bioinformatics/btw152.

Li H. 2018. Minimap2: Pairwise alignment for nucleotide sequences. Bioinformatics. DOI: 10.1093/bioinformatics/bty191. 
bioRxiv preprint doi: https://doi org/10.1101/2020.10.28.359364; this version posted October 28,2020 . The copyright holder for this preprint (which was not certified by peer review) is the author/funder, who has granted bioRxiv a license to display the preprint in perpetuity. It is made available under aCC-BY-ND 4.0 International license.

De Maio N, Shaw LP, Hubbard A, George S, Sanderson ND, Swann J, Wick R, AbuOun M, Stubberfield E, Hoosdally SJ, Crook DW, Peto TEA, Sheppard AE, Bailey MJ, Read DS, Anjum MF, Walker AS, Stoesser N, consortium on behalf of the R. 2019. Comparison of long-read sequencing technologies in the hybrid assembly of complex bacterial genomes. Microbial Genomics 5:e00294. DOI: 10.1099/mgen.0.000294.

Marijon P, Chikhi R, Varré J-S. 2020. yacrd and fpa: upstream tools for long-read genome assembly. Bioinformatics. DOI: 10.1093/bioinformatics/btaa262.

Martinez-Hernandez F, Fornas O, Lluesma Gomez M, Bolduc B, De La Cruz Peña MJ, Martínez JM, Anton J, Gasol JM, Rosselli R, Rodriguez-Valera F, Sullivan MB, Acinas SG, Martinez-Garcia M. 2017. Single-virus genomics reveals hidden cosmopolitan and abundant viruses. Nature Communications 8. DOI: 10.1038/ncomms15892.

Mirzaei MK, Maurice CF. 2017. Ménage à trois in the human gut: interactions between host, bacteria and phages. Nature Reviews Microbiology 15:397-408. DOI: 10.1038/nrmicro.2017.30.

Moss EL, Maghini DG, Bhatt AS. 2020. Complete, closed bacterial genomes from microbiomes using nanopore sequencing. Nature Biotechnology 38:701-707. DOI: 10.1038/s41587-020-0422-6.

Nayfach S, Camargo AP, Eloe-fadrosh E, Roux S, Kyrpides N. 2020. CheckV: assessing the quality of metagenome-assembled viral genomes. bioRxiv:1-20.

Nelson WC, Maezato Y, Wu YW, Romine MF, Lindemann SR. 2016. Identification and resolution of microdiversity through metagenomic sequencing of parallel consortia. Applied and Environmental Microbiology. DOI: 10.1128/AEM.02274-15.

Nurk S, Meleshko D, Korobeynikov A, Pevzner PA. 2017. MetaSPAdes: A new versatile metagenomic assembler. Genome Research 27:824-834. DOI: 10.1101/gr.213959.116.

Oxford Nanopore Technologies Ltd. 2018. Medaka.

Roux S. 2015. ClusterGenomes.

Roux S, Brum JR, Dutilh BE, Sunagawa S, Duhaime MB, Loy A, Poulos BT, Solonenko N, Lara E, Poulain J, Pesant S, Kandels-Lewis S, Dimier C, Picheral M, Searson S, Cruaud C, Alberti A, Duarte CM, Gasol JM, Vaqué D, Bork P, Acinas SG, Wincker P, Sullivan MB, Vaque D, Bork P, Acinas SG, Wincker P, Sullivan MB, Coordinators TO. 2016. Ecogenomics and potential biogeochemical impacts of globally abundant ocean viruses. Nature 537:689-693. DOI: 10.1038/nature19366.

Roux S, Emerson JB, Eloe-Fadrosh EA, Sullivan MB. 2017. Benchmarking viromics: an in silico evaluation of metagenome-enabled estimates of viral community composition and diversity. PeerJ 5:e3817. DOI: 10.7717/peerj.3817.

Roux S, Enault F, Hurwitz BL, Sullivan MB. 2015. VirSorter: mining viral signal from microbial genomic data. PeerJ 3:e985. DOI: 10.7717/peerj.985.

Shagin DA, Lukyanov KA, Vagner LL, Matz M V. 1999. Regulation of average length of complex PCR product. Nucleic acids research 27:e23-i-e23-iii. DOI: 10.1093/nar/27.18.e23-i.

Shi M, Lin XD, Tian JH, Chen LJ, Chen X, Li CX, Qin XC, Li J, Cao JP, Eden JS, Buchmann J, Wang W, Xu J, Holmes EC, Zhang YZ. 2016. Redefining the invertebrate RNA virosphere. Nature. DOI: $10.1038 /$ nature20167. 
bioRxiv preprint doi: https://doi. org/10.1101/2020 10.28.359364: this version posted October 28,2020 . The copyright holder for this preprint (which was not certified by peer review) is the author/funder, who has granted bioRxiv a license to display the preprint in perpetuity. It is made available under aCC-BY-ND 4.0 International license.

Shkoporov AN, Clooney AG, Sutton TDS, Ryan FJ, Daly KM, Nolan JA, McDonnell SA, Khokhlova E V., Draper LA, Forde A, Guerin E, Velayudhan V, Ross RP, Hill C. 2019. The Human Gut Virome Is Highly Diverse, Stable, and Individual Specific. Cell Host and Microbe 26:527541.e5. DOI: 10.1016/j.chom.2019.09.009.

Trubl G, Jang H Bin, Roux S, Emerson JB, Solonenko N, Vik DR, Solden L, Ellenbogen J, Runyon AT, Bolduc B, Woodcroft BJ, Saleska SR, Tyson GW, Wrighton KC, Sullivan MB, Rich VI. 2018. Soil Viruses Are Underexplored Players in Ecosystem Carbon Processing. mSystems 3:121. DOI: 10.1128/msystems.00076-18.

Vaser R, Sović I, Nagarajan N, Šikić M. 2017. Fast and accurate de novo genome assembly from long uncorrected reads. Genome Research 27:737-746. DOI: 10.1101/gr.214270.116.

Walker BJ, Abeel T, Shea T, Priest M, Abouelliel A, Sakthikumar S, Cuomo CA, Zeng Q, Wortman J, Young SK, Earl AM. 2014. Pilon: An integrated tool for comprehensive microbial variant detection and genome assembly improvement. PLoS ONE 9:e112963. DOI: 10.1371/journal.pone.0112963.

Warwick-Dugdale J, Solonenko N, Moore K, Chittick L, Gregory AC, Allen MJ, Sullivan MB, Temperton B. 2019. Long-read viral metagenomics captures abundant and microdiverse viral populations and their niche-defining genomic islands. PeerJ 7:e6800. DOI: 10.7717/peerj.6800.

Wick RR. 2017. Porechop. Github https://github. com/rrwick/Porechop.

Wick RR, Holt KE. 2020. Benchmarking of long-read assemblers for prokaryote whole genome sequencing. F1000Research 8. DOI: 10.12688/f1000research.21782.3.

Wolf YI, Silas S, Wang Y, Wu S, Bocek M, Kazlauskas D, Krupovic M, Fire A, Dolja V V, Koonin E V. 2020. Doubling of the known set of RNA viruses by metagenomic analysis of an aquatic virome. Nature Microbiology 5:1262-1270. DOI: 10.1038/s41564-020-0755-4.

Yuan Y, Gao M. 2017. Jumbo Bacteriophages: An Overview. Frontiers in microbiology 8:403. DOI: 10.3389/fmicb.2017.00403.

Zhong Z-P, Rapp JZ, Wainaina JM, Solonenko NE, Maughan H, Carpenter SD, Cooper ZS, Jang H Bin, Bolduc B, Deming JW, Sullivan MB. 2020. Viral Ecogenomics of Arctic Cryopeg Brine and Sea Ice. mSystems. DOI: 10.1128/msystems.00246-20. 
A Experiment 1: laboratory optimizations

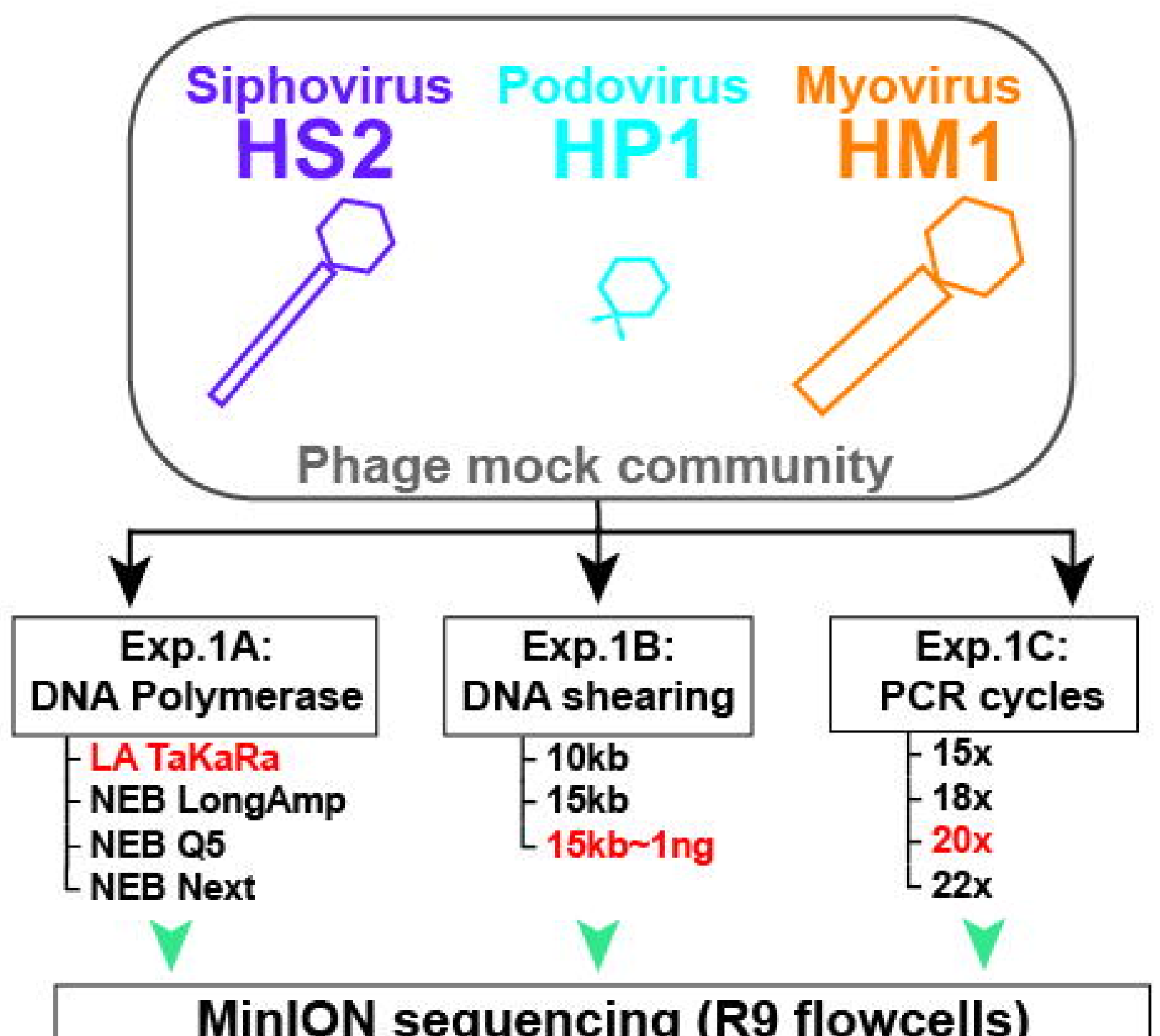

MinION sequencing (R9 flowcells)
B

Experiment 2: Informatics benchmarking

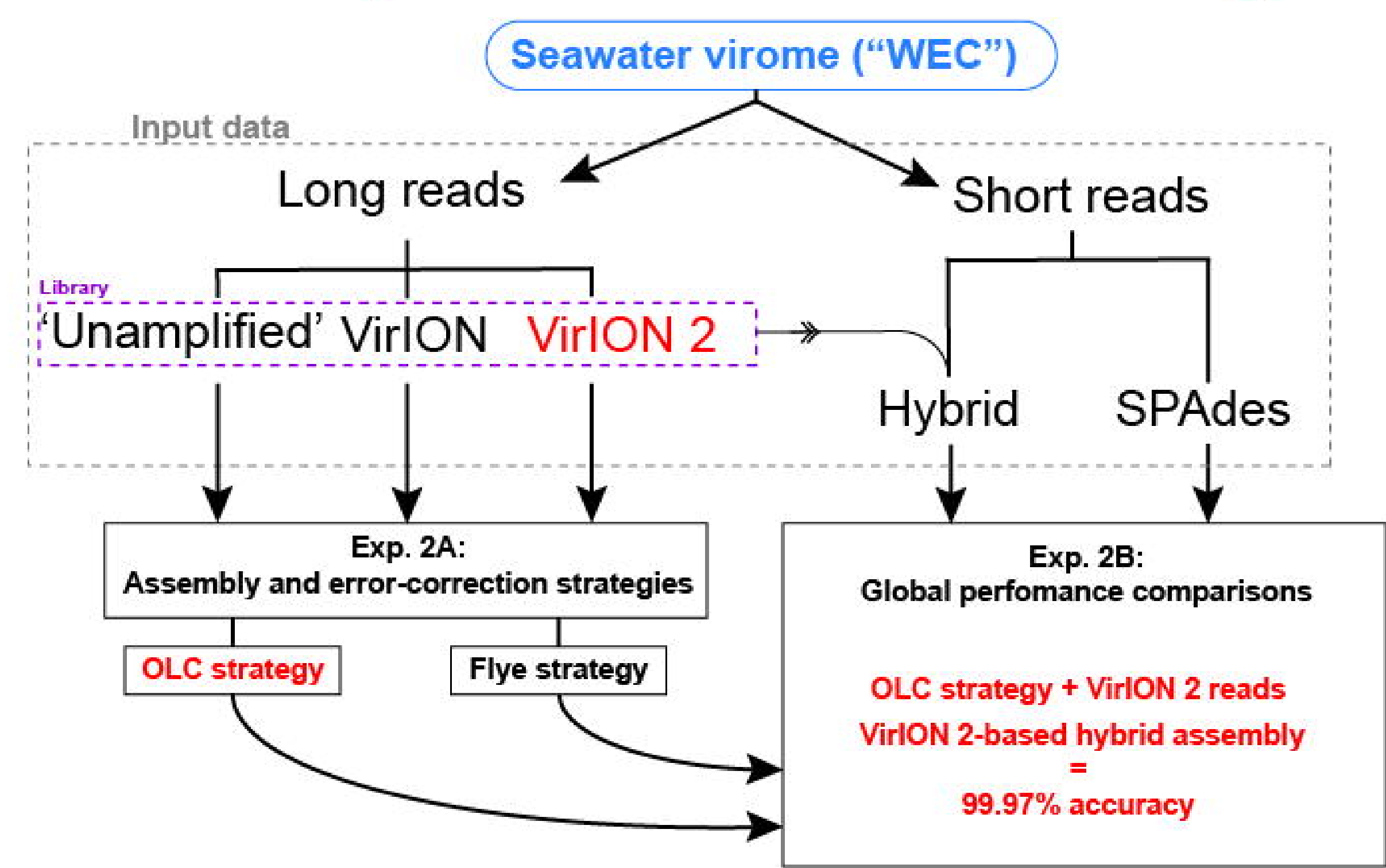

\section{Seawater virome ("WEC")}

Short reads

Hybrid SPAdes

Exp. 2B:

OLC strategy + VirION 2 reads

=
$99.97 \%$ accuracy 

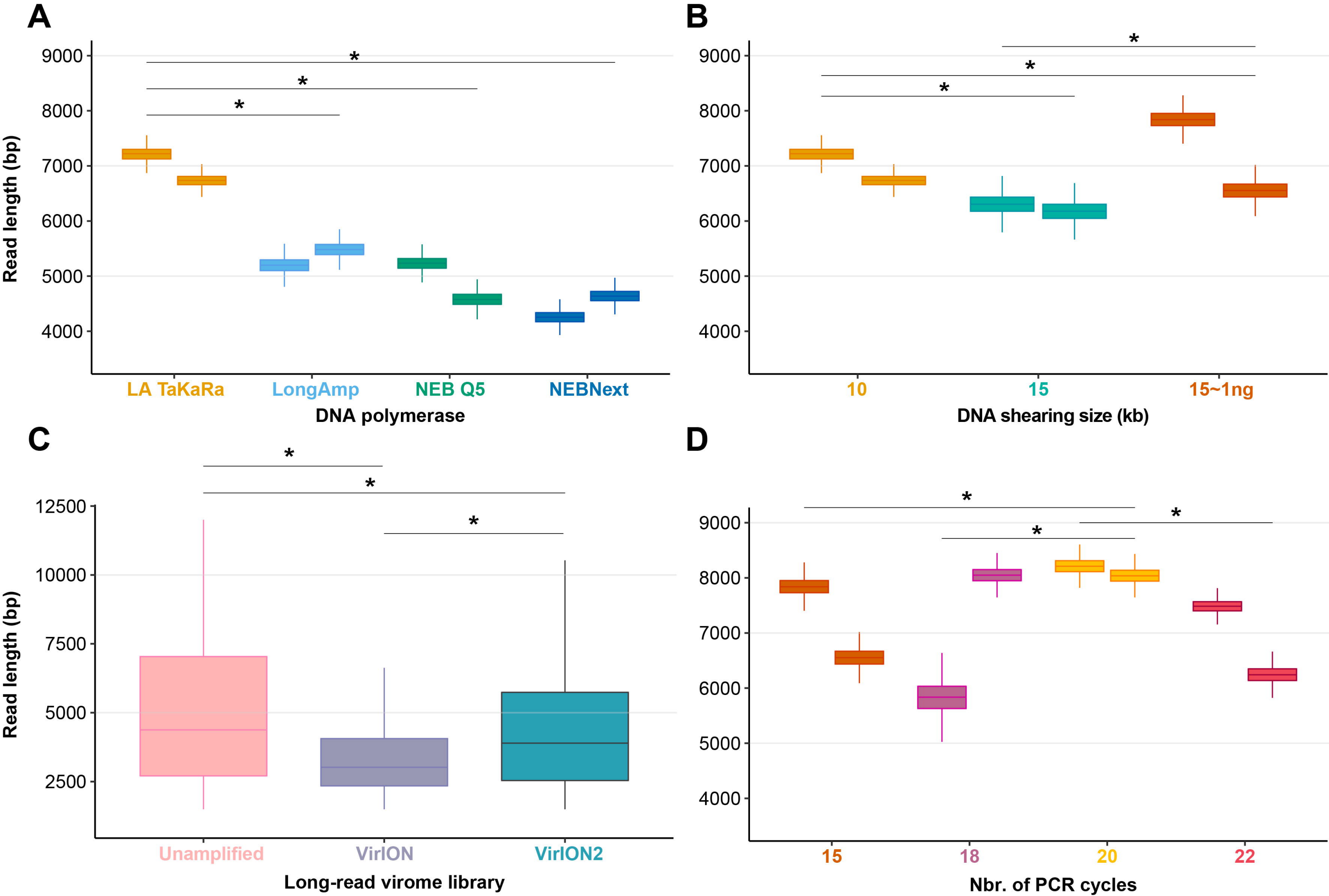

D

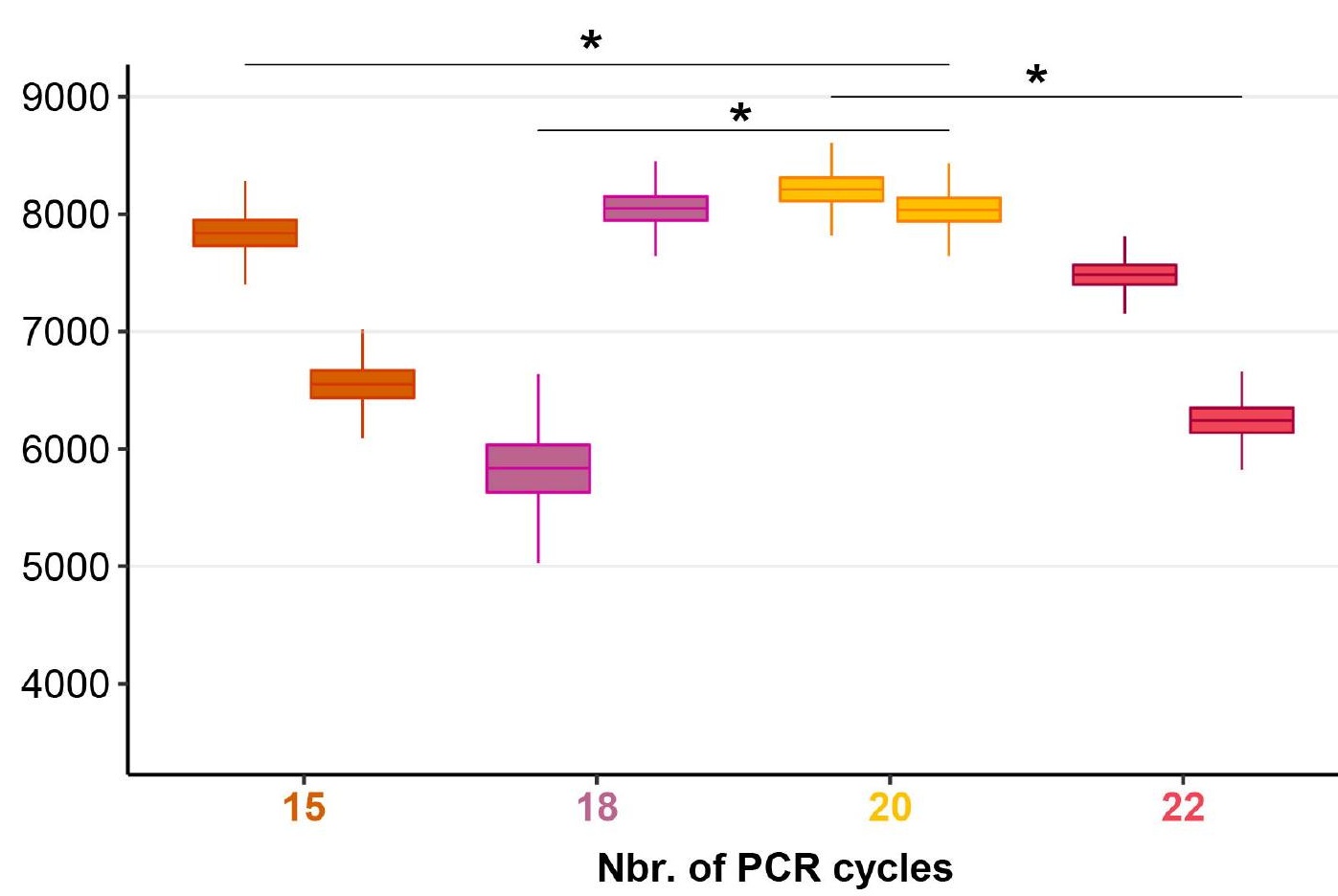


B

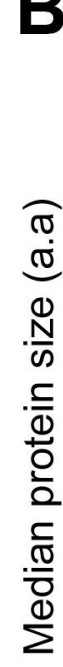

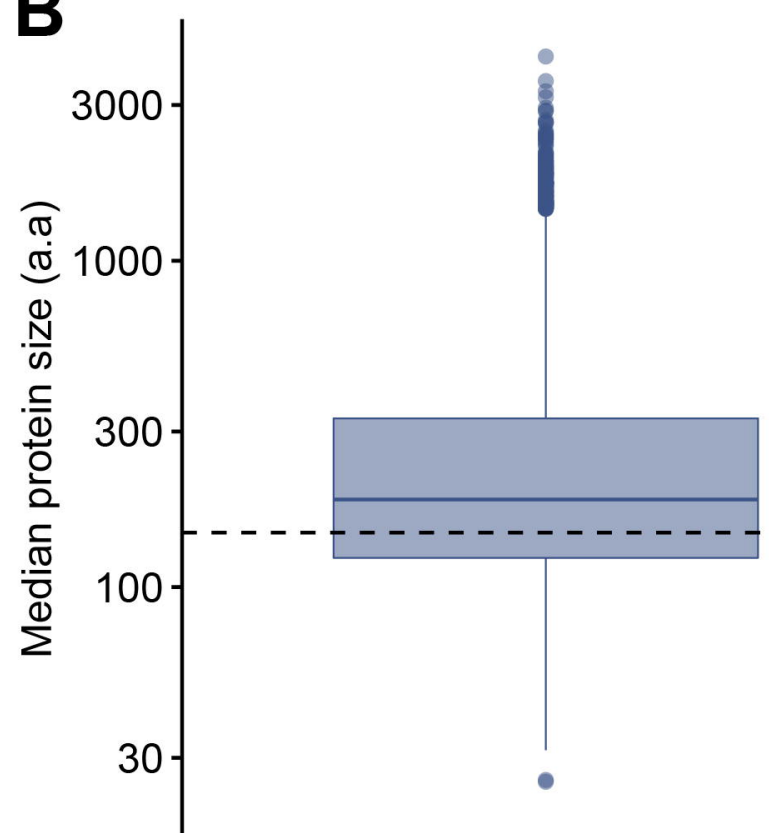

Nextera

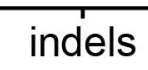

mismatches

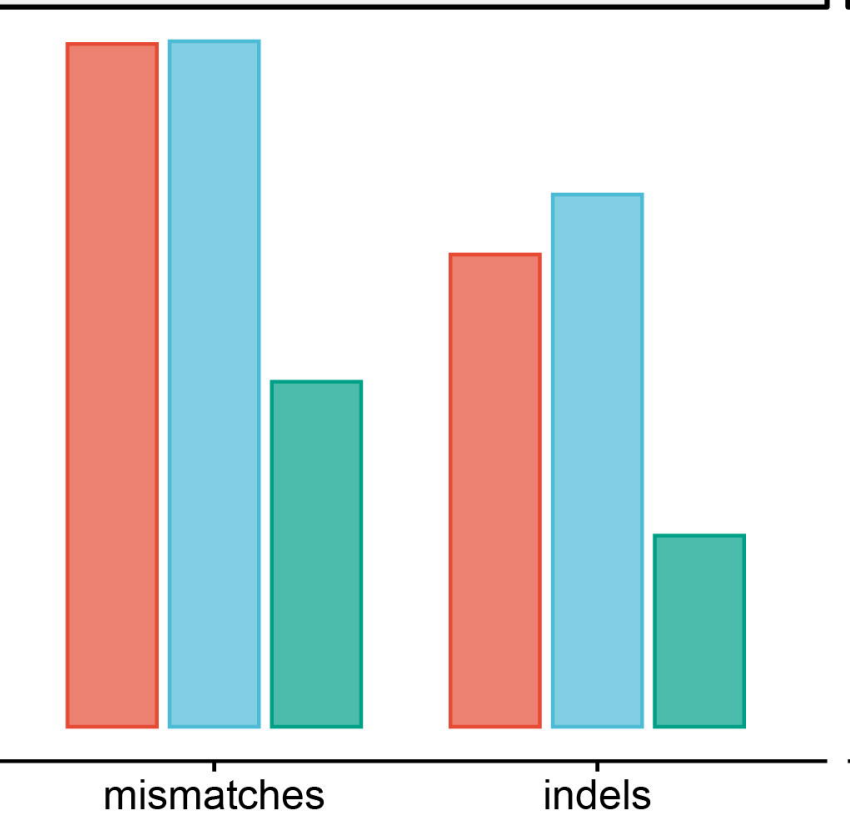

indels

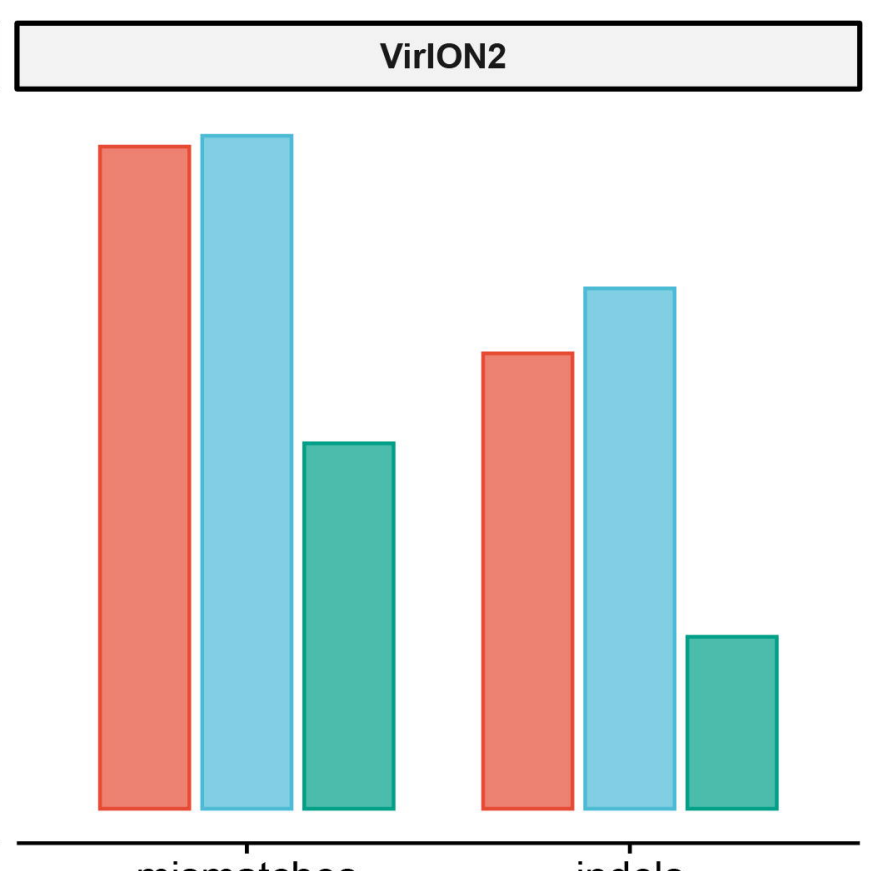

mismatches

indels

Correction level $\square$ Full OLC $\square$ Full Flye $\square$ Hybrid

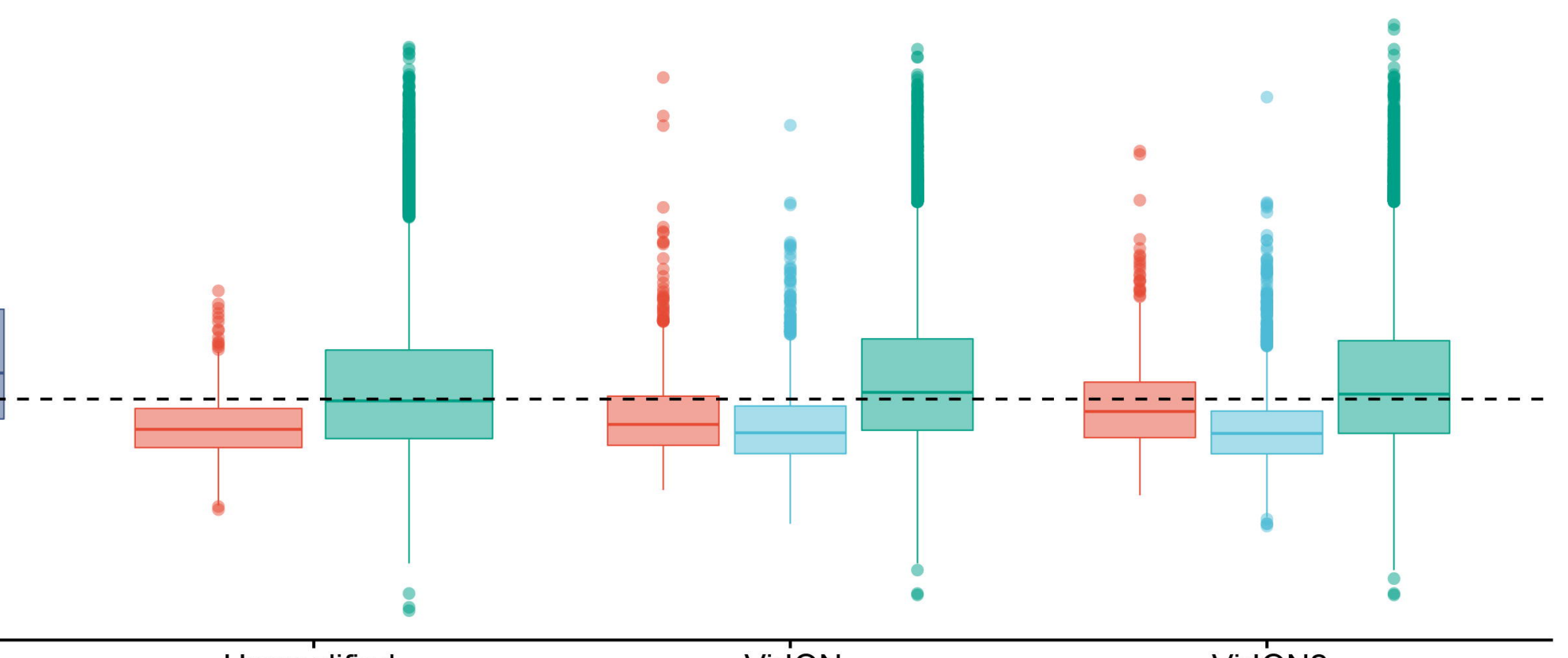

Unamplified

ViriON

VirlON2

Assembly Full OLC Full Flye Hybrid 


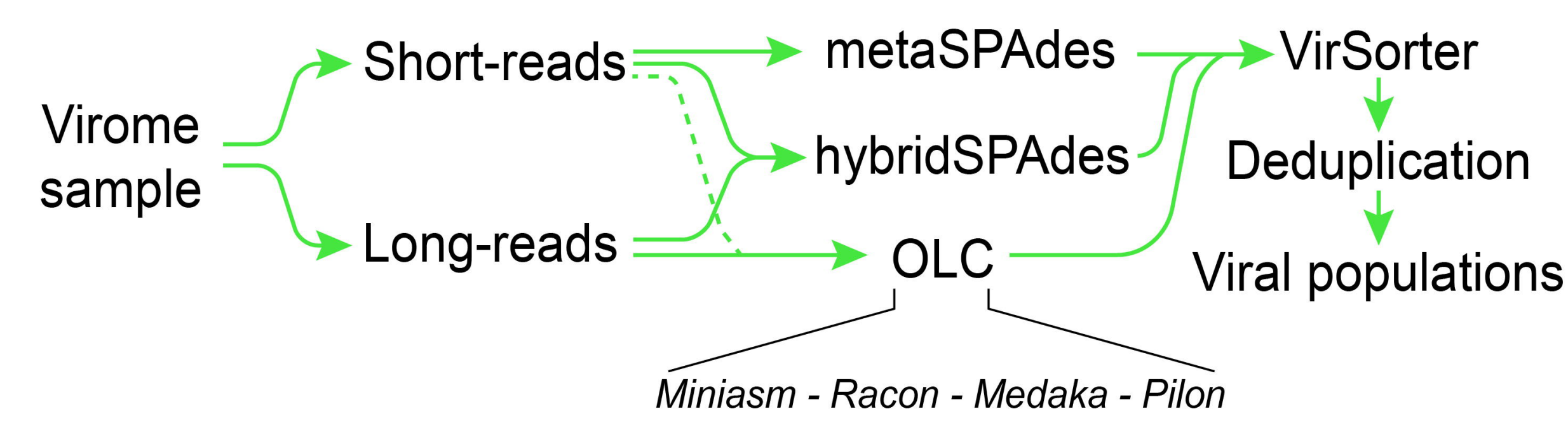

\section{C}

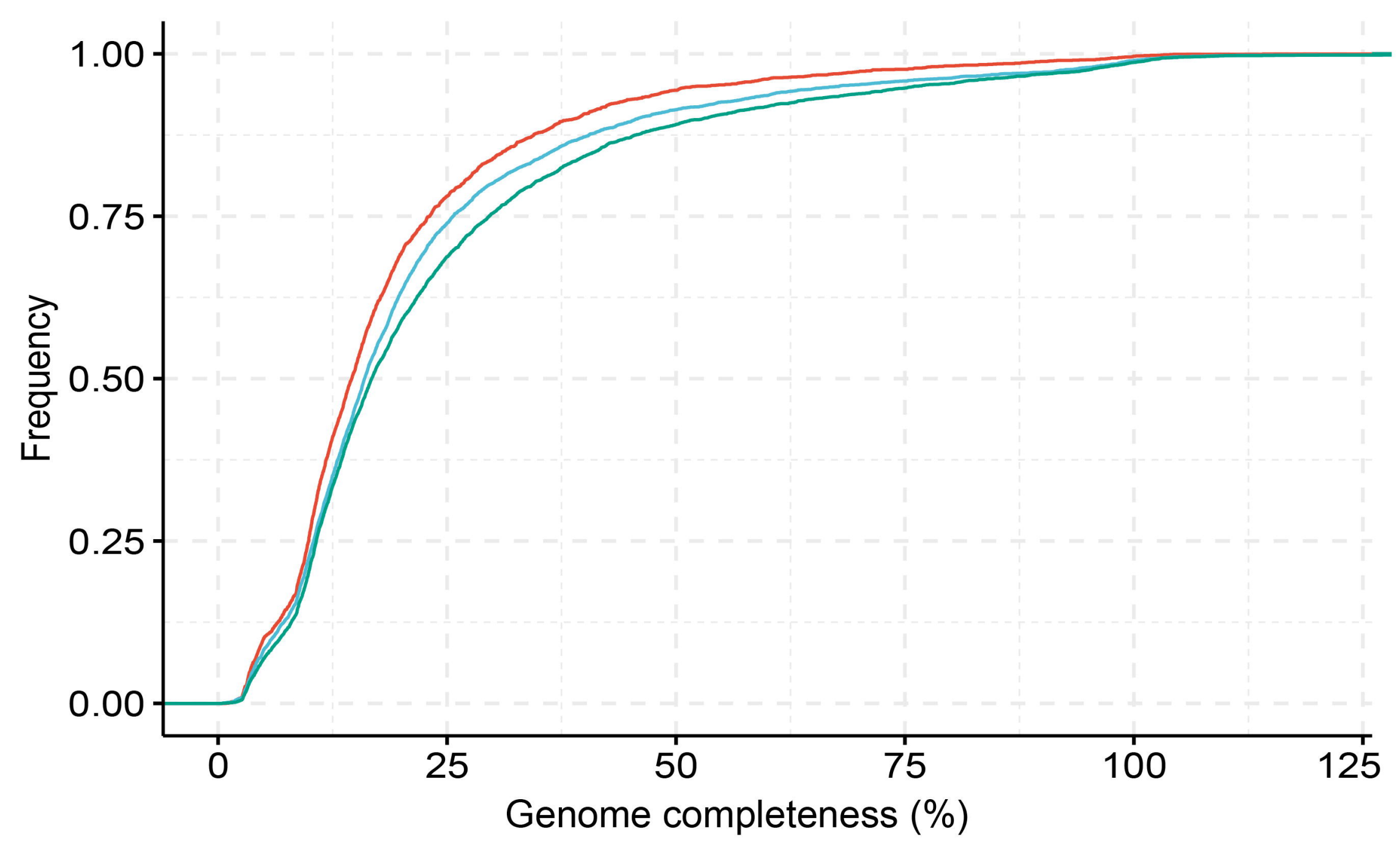

\section{B}

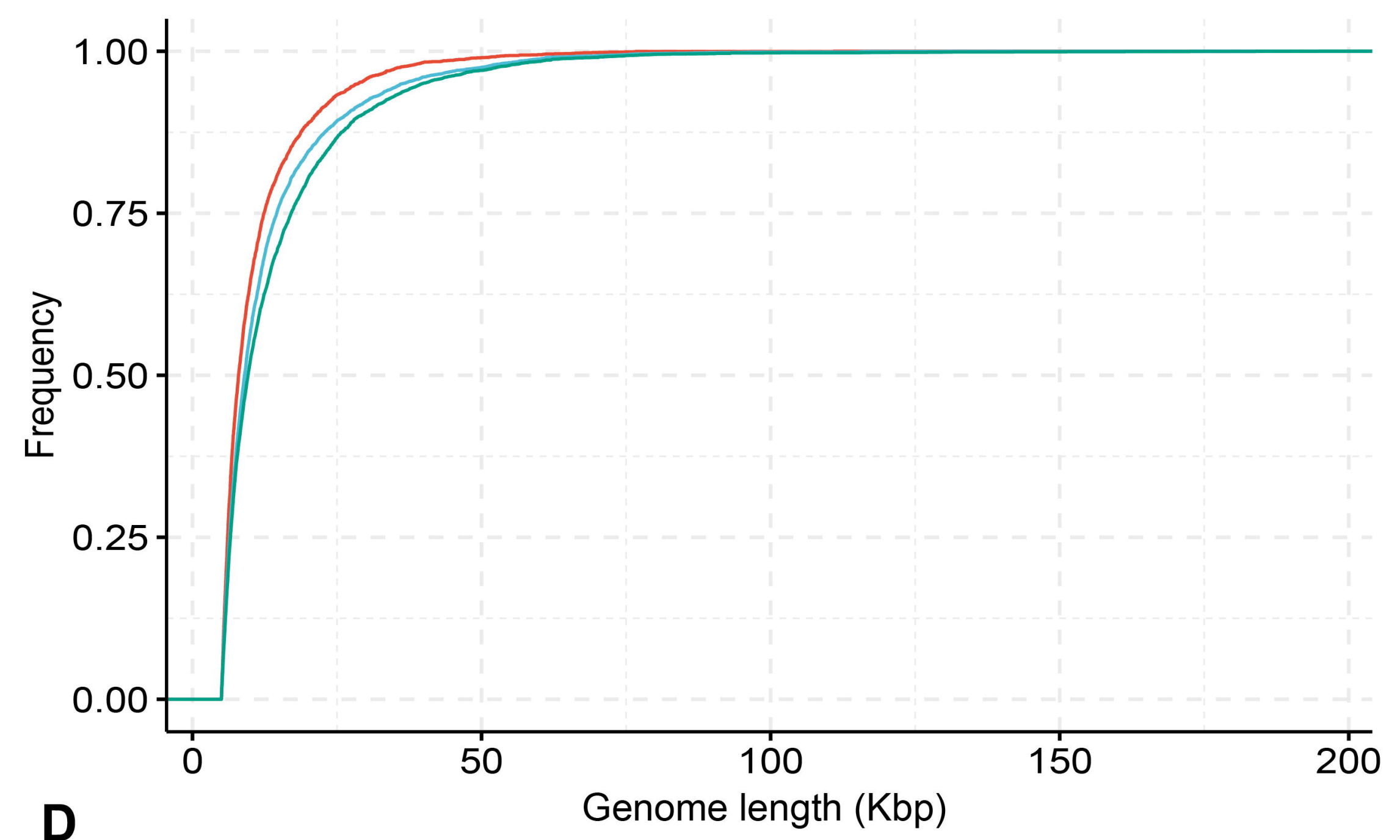

D

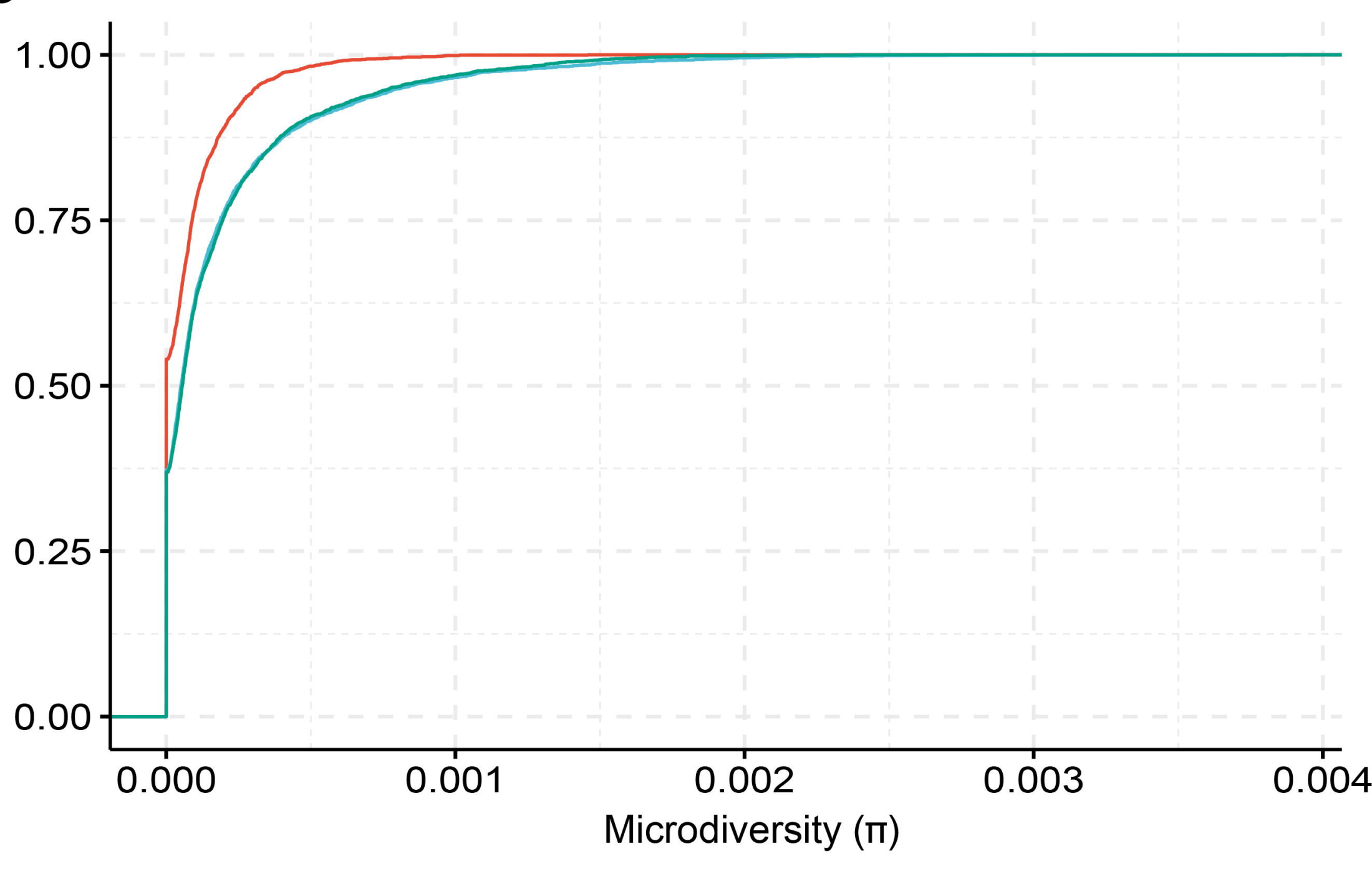

Short-reads VirlON VirlON2 


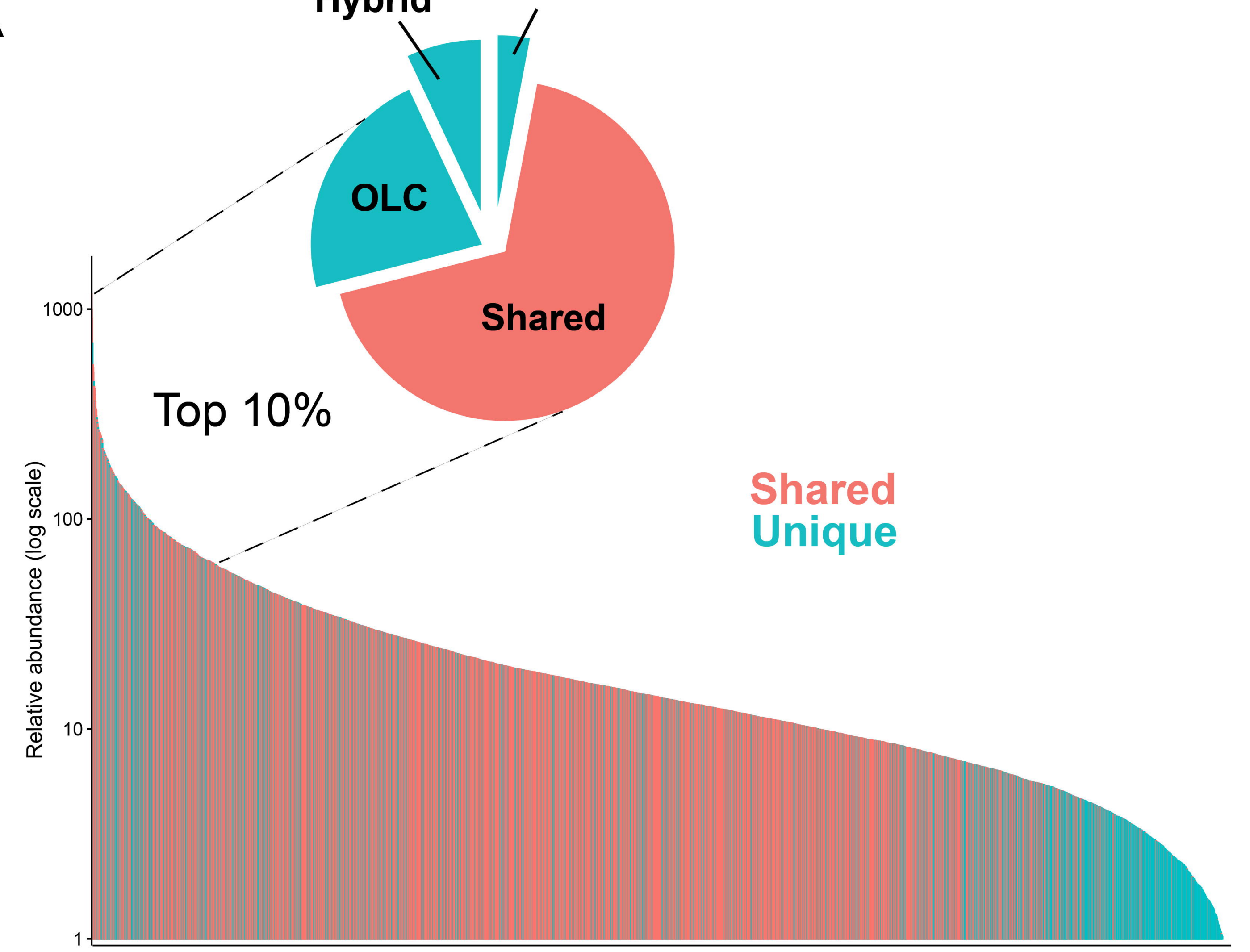

B

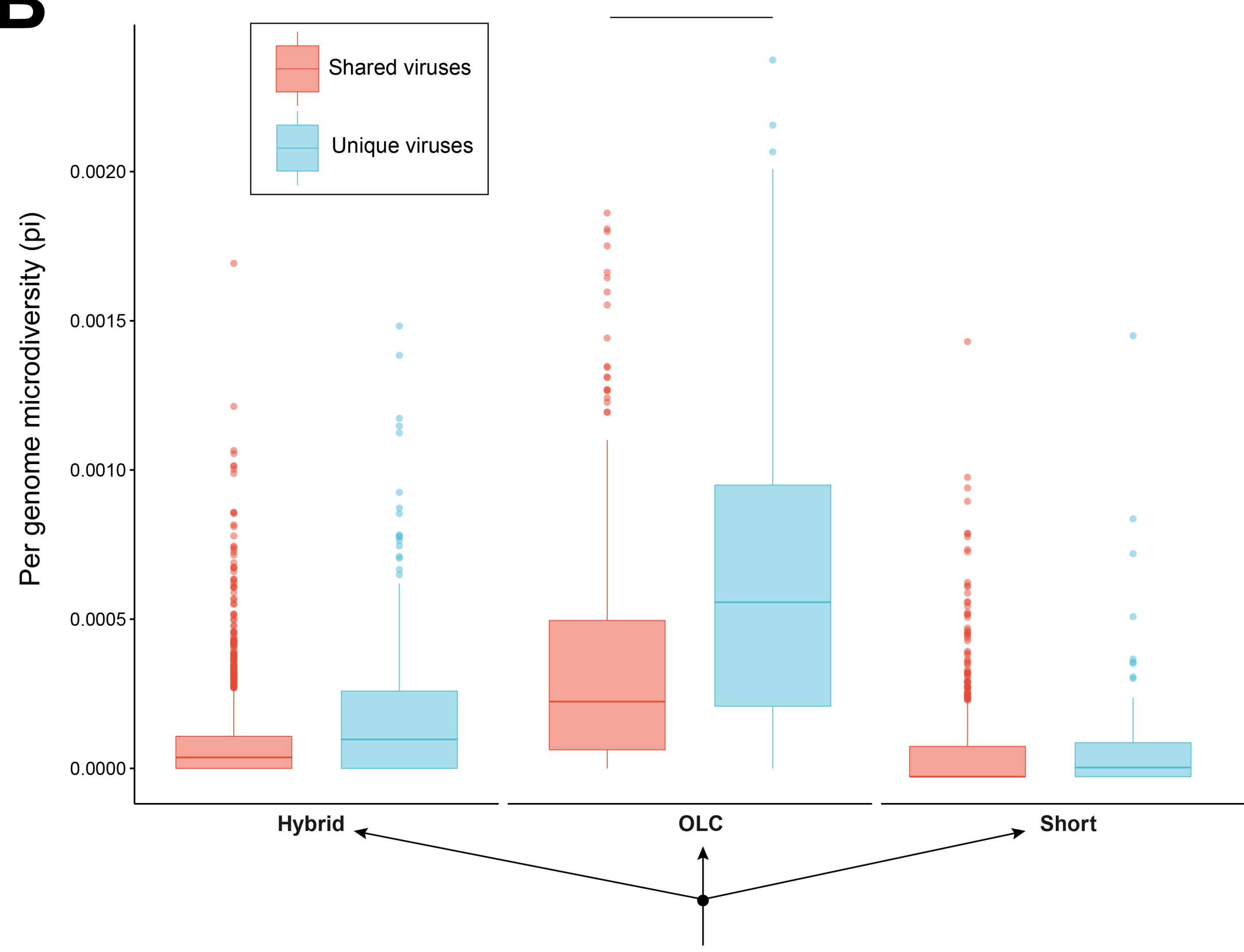

VirlON2-enhanced virome 


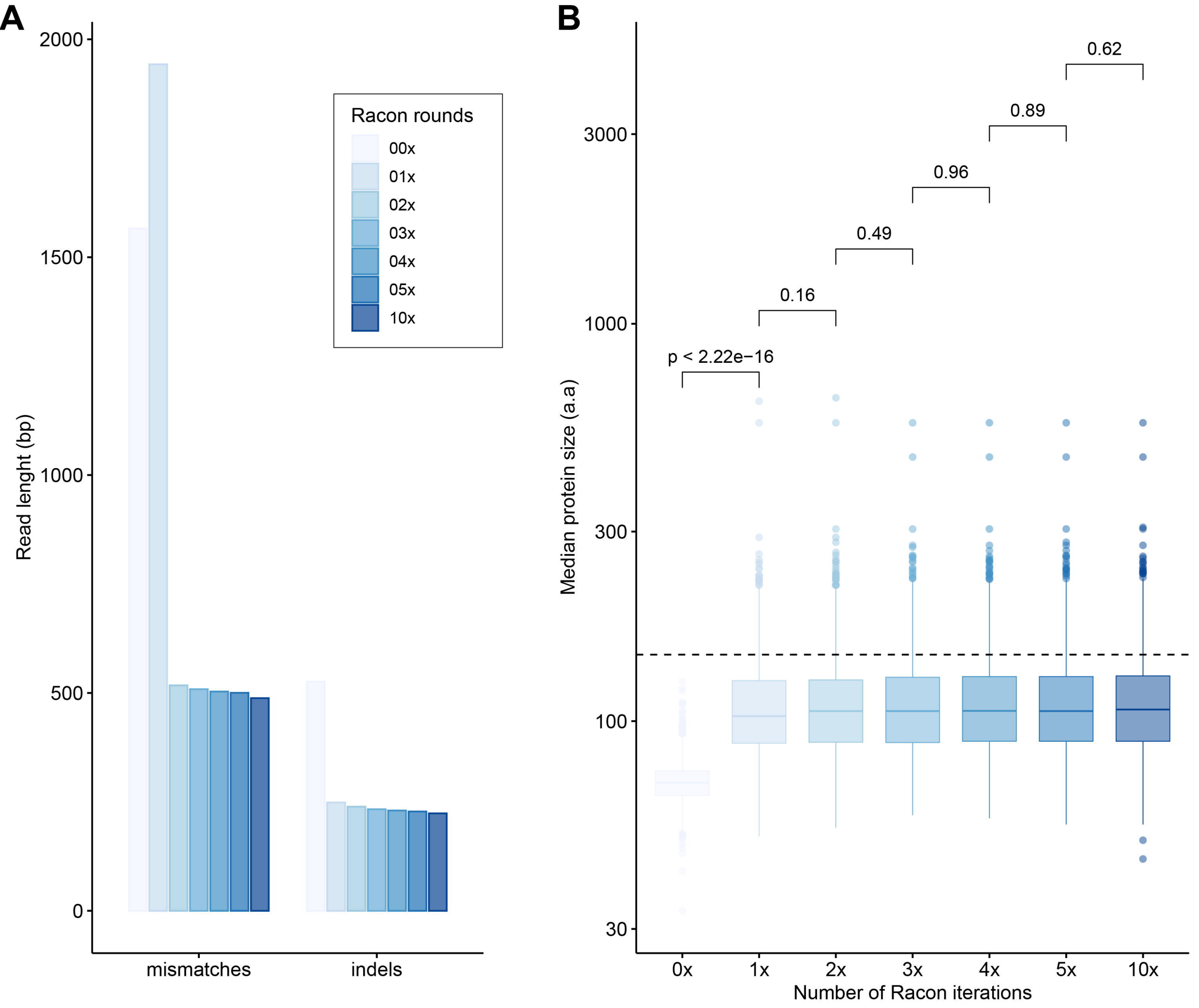



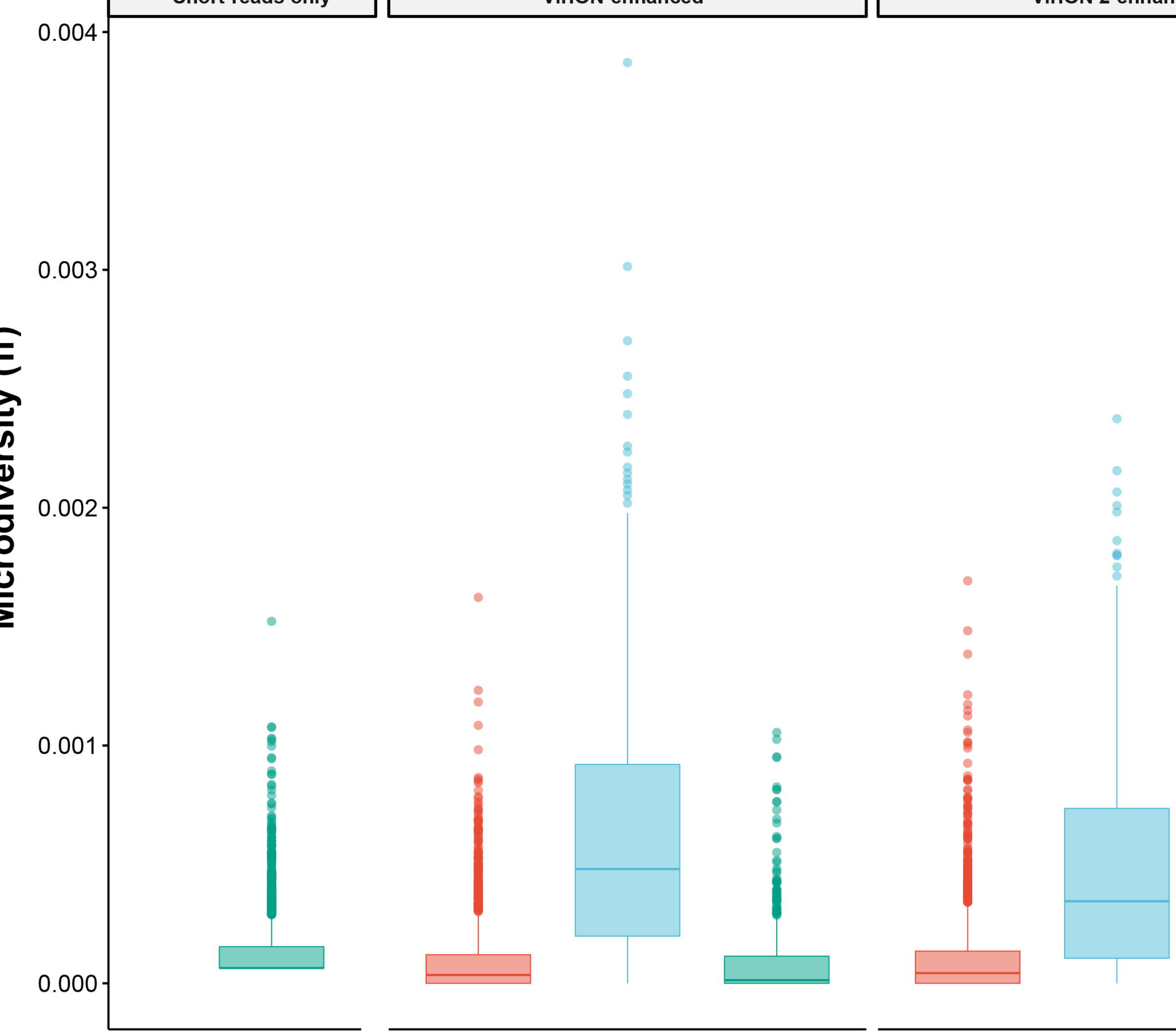